\title{
Renal Association Clinical Practice Guideline on Anaemia of Chronic Kidney Disease
}

\author{
Dr Ashraf Mikhail, ${ }^{a}$ Dr Rajesh Shrivastava, ${ }^{b}$ and Dr Donald Richardson ${ }^{c}$ \\ ${ }^{a}$ Consultant Nephrologist, Morriston Hospital, Swansea \\ ${ }^{\mathrm{b}}$ Associate Specialist, Morriston Hospital, Swansea \\ ${ }^{c}$ Consultant Nephrologist, York District Hospital, Yorkshire
}

\section{Key Words}

anaemia $\cdot$ chronic kidney disease $\cdot$ erythropoietin stimulating agents · iron - ferritin . blood transfusion . posttransplantation anaemia

\section{Introduction}

This clinical practice guideline provides recommendations on the management of anaemia of chronic kidney disease (CKD) and serves as an update of the 4th edition module published online in 2007. The recommendations in this update have been graded using the modified GRADE system to indicate both the strength of each recommendation (strong or weak) and level of evidence for the recommendation (A-D) $[1,2]$. As in the previous module The Renal Association (RA) endorses the NICE Guidelines for Anaemia Management in Chronic Kidney Disease (CKD) 2006 [3].

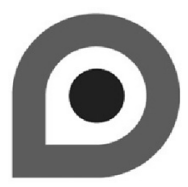

NHS Evidence Accreditation Mark
These guidelines are an updated version of the previous 'Complications of CKD Guidelines - Anaemia Section'. For this updated version, a systematic literature review was performed using MEDLINE \& PUBMED, focusing on the topics of:

- Renal anaemia;

- Anaemia and CKD;

- Iron deficiency;

- Iron therapy;

- Iron Toxicity;

- EPO, ESA;

- Anaemia and dialysis;

- Blood Transfusion and dialysis;

- Renal transplant and anaemia;

- Renal transplant and EPO;

- Renal transplant and blood transfusion;

- Immunosuppression and anaemia;

- Immunosuppression and EPO;

- Immunosuppression and blood transfusion.
C) 2011 S. Karger AG, Basel

$1160-2110 / 11 / 1185-000101 \$ 38.00 / 0$

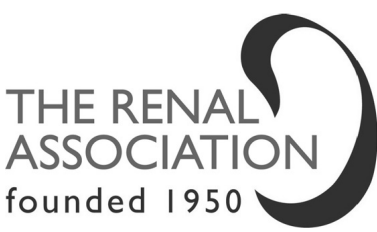

Dr Ashraf Mikhail, Dr Rajesh Shrivastava, and Dr Donald Richardson Email: Ashraf.mikhail@wales.nhs.uk or Donald.Richardson@York.NHS.UK 
The search covered the period from January 2007 to November 2009. Articles not written in English were not assessed. Articles available in abstract forms; letters; case reports; editorials or review articles were also excluded. Articles were assessed for relevance to the guideline topic, eligibility for inclusion in the evidence base for that guideline and methodological quality. Articles were considered of particular relevance if they were describing:

- Prospective randomised or quasi-randomised trials;

- Controlled trials;

- Meta-analysis of several trials;

- Cochrane systematic reviews.
Where evidence was available from RCTs and systematic reviews, recommendations were based on these publications. Where there was a lack of evidence from high-quality studies, recommendations were based on the best available evidence, taking into account the NICE guidelines [3], the European Renal Best Practice (ERBP) for Anaemia in CKD [4] and the KDOQI Guidelines for management of anaemia in CKD [5]. The guideline has been harmonised with the 2010 update of the NICE guidance on anaemia management in CKD [6]. The KDIGO website (www.kdigo.org) [7] is a useful site of reference for comparison of evidence based guidelines internationally.

\section{References}

1 Guyatt GH, Oxman AD, Vist GE et al. GRADE: an emerging consensus on rating quality of evidence and strength of recommendations. BMJ 2008;336:924-926

2 Uhlig K, MacLeod A, Craig J et al. Grading evidence and recommendations for clinical practice guidelines in nephrology. A position statement from Kidney Disease: Improving Global Outcomes (KDIGO). Kidney Int 2006;70:2058-2065

3 National Collaborating Centre for Chronic Conditions, Royal College of Physicians. Guideline on anaemia management in chronic kidney disease. 2006. National Institute for Clinical Excellence
4 Locatelli F, Aljama P, Barany P et al. Revised European best practice Guidelines for the management of anaemia in patients with chronic renal failure. Nephrol Dial Transplant 2004;19(Suppl 2):ii1-47

5 KDOQI; National Kidney Foundation Clinical practice guidelines and clinical practice recommendations for anaemia in chronic kidney disease in adults. Am J Kidney Dis. 2006 May; 47(5 Suppl 3):S16-S85

6 http://www.nice.org.uk/nicemedia/live/12958/50986/50986.pdf

7 www.kdigo.org 


\section{Summary of Clinical Practice Guidelines on Anaemia of CKD}

\section{Anaemia of CKD (Guidelines 1.1-1.6)}

Guideline 1.1 - Evaluation of anaemia - Screening for anaemia

We recommend that haemoglobin $(\mathrm{Hb})$ levels should be tested at least annually in CKD patients. (1B)

\section{Guideline 1.2 - Evaluation of anaemia -}

\section{Haemoglobin level}

We recommend that all patients with chronic anaemia associated with chronic kidney disease (CKD) should be investigated for possible treatment, irrespective of the stage of kidney disease or requirement for renal replacement therapy. (1A)

Anaemia should be evaluated in CKD patients with $\mathrm{Hb}<11 \mathrm{~g} / \mathrm{dL}$ or symptoms attributable to anaemia.

\section{Guideline 1.3 - Evaluation of anaemia - Renal function}

We suggest that CKD should be considered as a possible cause of anaemia when the glomerular filtration rate (GFR) is $<60 \mathrm{ml} / \mathrm{min} / 1.73 \mathrm{~m}^{2}$. It is more likely to be the cause if the GFR is $<30 \mathrm{mls} / \mathrm{min} / 1.73 \mathrm{~m}^{2}(<45$ in diabetics) and no other cause, i.e. blood loss, folic acid or vitamin B12 deficiency, is identified. (2B)

\section{Guideline 1.4 - Evaluation of anaemia -}

\section{Erythropoietin measurement}

We recommend that measurement of erythropoietin levels should not routinely be considered for the diagnosis or management of anaemia for patients with CKD. (1A)

\section{Guideline 1.5 - Evaluation of anaemia - Baseline investigations}

We recommend that initial clinical and laboratory evaluation of anaemia should be performed prior to initiation of treatment for anaemia in CKD patients. (1A)

\section{Guideline 1.6 - Evaluation of anaemia - Baseline investigations}

We recommend that laboratory evaluation should include the following tests (1B):

- Full blood count (FBC) including - in addition to the $\mathrm{Hb}$ concentration - red blood cell indices (mean corpuscular haemoglobin $[\mathrm{MCH}]$, mean corpuscular volume $[\mathrm{MCV}]$, mean corpuscular haemoglobin concentration $[\mathrm{MCHC}])$, white blood cell count, differential count and platelet count.

- Absolute reticulocyte count to assess bone marrow responsiveness (if indicated).

- Serum ferritin to assess iron stores.

- Serum transferrin saturation (TSAT) or reticulocyte $\mathrm{Hb}$ content $(\mathrm{CHr})$ to assess adequacy of iron for erythropoiesis.

- Percentage of hypochromic red blood cells (HRC).

- Plasma/serum C-reactive protein (CRP) - to assess inflammation.

Based on the initial assessment and in selected cases, the following tests may be useful to diagnose the cause of anaemia in some patients with CKD:

- Serum B12 and red cell folate concentrations.

- Tests for haemolysis (plasma/serum levels of haptoglobin, lactate dehydrogenase, bilirubin, Coombs' test).

- Plasma/serum and/or urine protein electrophoresis.

- Hb electrophoresis and bone marrow examination.

\section{Anaemia of CKD (Guidelines 2.1-2.10)}

Guideline 2.1 - Treatment of Anaemia Erythropoiesis Stimulating Agents

We recommend that treatment with Erythropoiesis Stimulating Agents (ESAs) should be offered to patients with anaemia of CKD who are likely to benefit in terms of quality of life and physical function and to avoid transfusion in patients considered suitable for transplantation. (1A)

\section{Guideline 2.2 - Treatment of Anaemia - Choice of} ESA

We recommend that the decision on the choice of ESA is based on local availability of ESAs. (1B)

\section{Guideline 2.3 - Treatment of Anaemia with ESA} therapy - Target $\mathrm{Hb}$

We recommend that patients with CKD on ESA therapy should achieve $\mathrm{Hb}$ between 10-12 g/dl. (1B)

Guideline 2.4 - Treatment of Anaemia without ESA therapy - Target $\mathrm{Hb}$

We recommend that these $\mathrm{Hb}$ targets apply exclusively to patients receiving ESA and are not intended to apply 
to the treatment of iron deficiency in patients receiving iron therapy without the use of ESAs. (1B)

\section{Guideline 2.5 - Treatment of Anaemia - Initial ESA dose}

We recommend that the initial ESA dose should be determined by the patient's $\mathrm{Hb}$ level, the target $\mathrm{Hb}$ level, the observed rate of increase in $\mathrm{Hb}$ level and clinical circumstances. (1B)

\section{Guideline 2.6 - Treatment of Anaemia with ESA} therapy - Route of administration

We suggest that the route of ESA administration should be determined by the CKD stage, treatment setting, efficacy, safety, and class of ESA used; subcutaneous (SC) route is the access of choice in non-HD patients, while convenience may favour intravenous (IV) administration in HD patients. (2B)

\section{Guideline 2.7 - Treatment of Anaemia with ESA} therapy - Frequency of administration

We suggest that the frequency of administration should be determined by the CKD stage, treatment setting and class of ESA. Less frequent administration using long acting ESAs may be the treatment of choice in non-HD patients. (2B)

\section{Guideline 2.8 - Treatment of Anaemia with ESA}

Therapy - ESA dose adjustments

We recommend that adjustments to ESA doses should be considered when $\mathrm{Hb}$ is $<10.5$ or $>11.5 \mathrm{~g} / \mathrm{dL}$ in order to balance benefit and safety to patients given the current evidence base. These thresholds for intervention should achieve a population distribution centred on a mean of $11 \mathrm{~g} / \mathrm{dl}$ with a range of $10-12$. (1B)

\section{Guideline 2.9 - Treatment of Anaemia with ESA} Therapy - ESA dose adjustments

We suggest that ESA doses should ideally be decreased rather than withheld when a downward adjustment of $\mathrm{Hb}$ level is needed. (2B)

\section{Guideline 2.10 - Treatment of Anaemia with ESA}

\section{Therapy - ESA dose adjustments}

We recommend that ESA administration in ESAdependent patients should continue during acute illness, surgical procedures or any other cause of hospitalisation. (1B)

\section{Anaemia of CKD (Guidelines 3.1-3.4)}

Guideline 3.1 - Treatment of Anaemia with Iron therapy - Iron repletion

We recommend that patients should be iron replete to achieve and maintain target $\mathrm{Hb}$ whether receiving ESAs or not. (1A)

\section{Guideline 3.2 - Treatment of Anaemia with Iron} therapy - Initiation of ESA and iron status

We recommend that ESA therapy should not be initiated in the presence of absolute iron deficiency (ferritin $<100 \mathrm{ng} / \mathrm{ml}$ ). In patients with functional iron deficiency, iron supplements should be given prior to or when initiating ESA therapy. (1A)

\section{Guideline 3.3 - Treatment of Anaemia with Iron} therapy - Route of Administration

We suggest that oral iron will, in general, be sufficient to attain and maintain the $\mathrm{Hb}$ above targets in ESA treated CKD patients not yet requiring dialysis and in those on peritoneal dialysis (PD). (2B)

In contrast most $\mathrm{HD}$ patients will require intravenous iron. $(2 \mathrm{~A})$

\section{Guideline 3.4 - Treatment of Anaemia with Iron} therapy - Upper limit for iron therapy

We recommend that serum ferritin should not exceed $800 \mathrm{ng} / \mathrm{ml}$ in patients treated with iron, and to achieve this iron management should be reviewed when the ferritin is $>500 \mathrm{ng} / \mathrm{ml}$. (1B)

\section{Anaemia of CKD (Guidelines 4.1-4.5)}

Guideline 4.1 - Monitoring of Treatment - Hb during ESA therapy

We recommend that $\mathrm{Hb}$ concentration should be monitored every month in the correction phase and every 1-3 months for stable patients in the maintenance phase. More frequent monitoring will depend on clinical circumstances. (1B)

\section{Guideline 4.2 - Monitoring of Treatment - Iron therapy}

We recommend regular monitoring of iron status (1-3 monthly) during treatment to avoid toxicity (1B): a serum ferritin consistently greater than $800 \mathrm{ng} / \mathrm{ml}$ is suggestive of iron overload. (1B) 
Guideline 4.3 - Monitoring during Intravenous Iron Administration

We recommend that resuscitative medication and personnel trained to evaluate and resuscitate anaphylaxis should be present at each administration of iron dextran. (1A)

\section{Guideline 4.4 - Monitoring of Treatment - Resistance to ESA therapy}

We recommend that inadequate response ('resistance') to ESA therapy is defined as failure to reach the target $\mathrm{Hb}$ level despite SC epoetin dose $>300 \mathrm{IU} / \mathrm{kg} /$ week $(450 \mathrm{IU} /$ $\mathrm{kg} /$ week IV epoetin), or darbepoetin dose $>1.5 \mathrm{mcg} / \mathrm{kg} /$ week. Hyporesponsive patients who are iron replete should be screened clinically and by investigations for other common causes of anaemia. (1A)

\section{Guideline 4.5 - Monitoring of treatment - Hypertension during ESA therapy}

We recommend that blood pressure should be monitored in all patients receiving ESAs and, if present, hypertension be treated by volume removal and/or hypotensive drugs. (1A)

\section{Anaemia of CKD (Guidelines 5.1-5.2)}

\section{Guideline 5.1 - Blood Transfusion}

We recommend that in patients with anaemia of CKD, especially those in whom renal transplantation is an option, red blood cell transfusion should be avoided if possible. (1A)

\section{Guideline 5.2 - Blood Transfusion}

We recommend if red blood cell transfusion becomes essential (usually in the setting of acute blood loss, acute haemolysis or severe sepsis) transfusion should be based on policies set by local transfusion guidelines rather than $\mathrm{Hb}$ targets for ESA therapy in chronic anaemia of CKD. (1B)

\section{Anaemia of CKD (Guideline 6.1)}

\section{Guideline 6.1 - Post-transplantation Anaemia}

We recommend that the treatment guidelines for anaemia in renal transplant patients should be similar to those for CKD patients not on dialysis. (1B)

\section{Summary of Audit Measures}

1. Proportion of CKD patients with eGFR $<30 \mathrm{ml} /$ min by 4 variable MDRD method with an annual $\mathrm{Hb}$ level

2. Proportion of patients starting an ESA without prior measurement of serum ferritin and/or TSAT

3. Proportion of patients on renal replacement therapy with $\mathrm{Hb}$ level $<10$ who are not prescribed an ESA

4. Each renal unit should audit the type, route and frequency of administration and weekly dose of ESA prescribed

5. The proportion of CKD stage $4-5$ patients with $\mathrm{Hb} 10-12 \mathrm{~g} / \mathrm{dl}$

6. The proportion of patients treated with an ESA with $\mathrm{Hb}>12 \mathrm{~g} / \mathrm{dl}$

7. Each renal unit should monitor ESA dose adjustments

8. Proportion of patients with serum ferritin levels $<100 \mathrm{ng} / \mathrm{ml}$ at start of treatment with ESA

9. Proportion of predialysis and PD patients receiving iron therapy; type: oral vs. parenteral

10. Proportion of HD patients receiving IV iron

11. Prevalence of resistance to ESA among renal replacement therapy patients

12. Proportion of HD patients who received a blood transfusion within the past year 


\section{Rationale for Clinical Practice Guidelines for Anaemia of CKD}

\section{Anaemia of CKD (Guidelines 1.1-1.6)}

\section{Guideline 1.1 - Evaluation of anaemia - Screening} for anaemia

We recommend that haemoglobin $(\mathrm{Hb})$ levels should be tested at least annually in CKD patients. (1B)

\section{Audit measure}

Proportion of CKD patients with eGFR $<30 \mathrm{ml} / \mathrm{min}$ by 4 variable MDRD method with an annual $\mathrm{Hb}$ level

\section{Rationale}

There is not enough literature to suggest the ideal frequency of $\mathrm{Hb}$ testing in $\mathrm{CKD}$ patients who are not on ESA therapy. Alternatively data from clinical trials have shown that the rate of $\mathrm{Hb}$ decline in these patients is a gradual one $[1,2]$. In a Canadian study to assess the effect of ESA therapy on left ventricular mass in CKD patients [2] 172 patients were assigned to either receive therapy with erythropoietin $\alpha$ subcutaneously to maintain or achieve $\mathrm{Hb}$ level targets of 12.0 to $14.0 \mathrm{~g} / \mathrm{dL}$, or to the control/delayed treatment group with mean $\mathrm{Hb}$ levels of $9.0 \pm 0.5 \mathrm{~g} / \mathrm{dL}$. During 2 years follow up a significant proportion of patients eventually required ESA therapy. However, among those who did not require ESA therapy, mean $\mathrm{Hb}$ values remained relatively stable throughout the study period.

\section{Guideline 1.2 - Evaluation of anaemia - Haemoglobin level}

We recommend that all patients with chronic anaemia associated with chronic kidney disease (CKD) should be investigated for possible treatment, irrespective of the stage of kidney disease or requirement for renal replacement therapy. (1A)

Anaemia should be evaluated in CKD patients with $\mathrm{Hb}<11 \mathrm{~g} / \mathrm{dL}$ or symptoms attributable to anaemia.

\section{Rationale}

The Renal Association (RA) and Royal College of Physicians endorse the NICE Guidelines for Anaemia Management in Chronic Kidney Disease (CKD) 2006 [3]. The reader is referred to these guidelines as well as the European Renal Best Practice (ERBP) for Anaemia in CKD [4] and the KDOQI [5] Guidelines for management of anaemia in CKD. The KDIGO website (www.kdigo.org) [6] is a useful site of reference for comparison of evidence based guidelines internationally.

Anaemia is defined as having a $\mathrm{Hb}$ value below the established cut off defined by the World Health Organisation. Different defined groups have different cut offs. For adults:

- Men and postmenopausal women $\mathrm{Hb}<13.0 \mathrm{~g} / \mathrm{dl}$

- Premenopausal women $\mathrm{Hb}<12.0 \mathrm{~g} / \mathrm{dl}$

In 2006, KDOQI modified this definition by giving a single criterion for diagnosing anaemia in adult males $(\mathrm{Hb}<13.5 \mathrm{~g} / \mathrm{dl}$, regardless of age $)$ because the decrease in $\mathrm{Hb}$ among males aged $>60$ years is often attributable to associated co-morbidities [5].

In addition to gender, age and pregnancy other factors influence $\mathrm{Hb}$ level including smoking, altitude, race and genetic disorders (thalassaemia and sickle cell disease). In CKD a patient's anaemia should be defined using these same criteria. The degree of renal impairment affects the likelihood of any patient developing anaemia. Although current treatment with ESAs is not recommended unless $\mathrm{Hb}$ falls consistently below $11.0 \mathrm{~g} / \mathrm{dl}$, other causes of anaemia should be excluded in patients with $\mathrm{Hb}$ below normal range. The current definition for anaemia applies to adult patients older than 18 years, of all races and ethnic groups, and living at relatively low altitude $(<1,000 \mathrm{~m}$ or $3,000 \mathrm{ft})$ [7]. With increasing altitude, endogenous erythropoietin production is increased; as a result, $\mathrm{Hb}$ concentration can be expected to increase by about $0.6 \mathrm{~g} / \mathrm{dL}$ in women and $0.9 \mathrm{~g} / \mathrm{dL}$ in men for each $1,000 \mathrm{~m}$ of altitude above sea level [8].

\section{Guideline 1.3 - Evaluation of anaemia - Renal function}

We suggest that CKD should be considered as a possible cause of anaemia when the glomerular filtration rate (GFR) is $<60 \mathrm{ml} / \mathrm{min} / 1.73 \mathrm{~m}^{2}$. It is more likely to be the cause if the GFR is $<30 \mathrm{mls} / \mathrm{min} / 1.73 \mathrm{~m}^{2}(<45$ in diabetics) and no other cause, i.e. blood loss, folic acid or vitamin B12 deficiency, is identified. (2B)

\section{Audit measure}

Proportion of CKD patients with eGFR $<30 \mathrm{ml} / \mathrm{min}$ by 4 variable MDRD method [1] with an annual $\mathrm{Hb}$ level

\section{Rationale}

The prevalence of anaemia in patients with CKD increases as the GFR progressively falls [9]. NHANES 
III data demonstrate a prevalence of anaemia of 1\%, $9 \%$ and $33 \%$ in CKD patients with an eGFR of 60,30 and $15 \mathrm{ml} / \mathrm{min}$ respectively [10]. UK data of $>112,000$ unselected patients in the general population showed a population prevalence of CKD 3-5 of $4.9 \%$ [11]. In these patients the prevalence of gender specific anaemia ( $<12$ men: $<11$ women) was $12 \%$.

Anaemia is more prevalent among patients with diabetes. In addition, anaemia of CKD develops earlier in patients with diabetes compared with non-diabetics [12-16]. In a cross-sectional study involving over 800 patients with diabetes, anaemia has been found to be two to three times more prevalent in patients with diabetes compared with the general population at all levels of GFR [17].

\section{Guideline 1.4 - Evaluation of anaemia - Erythropoietin measurement}

We recommend that measurement of erythropoietin levels should not routinely be considered for the diagnosis or management of anaemia for patients with CKD. (1A)

\section{Rationale}

In renal anaemia, serum erythropoietin (EPO) levels are lower than appropriate for the degree of anaemia. In CKD patients with anaemia, erythropoietin titres are not lower but may be equal to or even higher than in normal non-anaemic individuals [18-20]. Measurement of erythropoietin level is very rarely helpful.

\section{Guideline 1.5 - Evaluation of anaemia - Baseline investigations}

We recommend that initial clinical and laboratory evaluation of anaemia should be performed prior to initiation of treatment for anaemia in CKD patients. (1A)

\section{Audit measure}

Proportion of patients starting an ESA without prior measurement of serum ferritin and/or TSAT

\section{Rationale}

Although relative erythropoietin deficiency is common among patients with anaemia and CKD, other potential causes should be identified or excluded. A clinical and laboratory evaluation of the cause of anaemia should precede initiation of ESA therapy. The recommended laboratory evaluation aims at assessing:
- The degree and cause of anaemia,

- Bone marrow responsiveness, and

- Iron stores and iron availability for erythropoiesis.

Anaemia due to causes other than erythropoietin deficiency should be suspected when:

- The severity of the anaemia is disproportionate to the deficit in renal function,

- There is evidence of iron deficiency,

- There is evidence of haemolysis, or

- There is evidence of bone marrow disorder as manifest by leucopaenia or thrombocytopaenia.

\section{Guideline 1.6 - Evaluation of anaemia - Baseline investigations}

We recommend that laboratory evaluation should include the following tests (1B):

- Full blood count (FBC) including - in addition to the $\mathrm{Hb}$ concentration - red blood cell indices (mean corpuscular haemoglobin $[\mathrm{MCH}]$, mean corpuscular volume $[\mathrm{MCV}]$, mean corpuscular haemoglobin concentration [MCHC]), white blood cell count, differential count and platelet count.

- Absolute reticulocyte count to assess bone marrow responsiveness (if indicated).

- Serum ferritin to assess iron stores.

- Serum transferrin saturation (TSAT) or reticulocyte $\mathrm{Hb}$ content $(\mathrm{CHr})$ to assess adequacy of iron for erythropoiesis.

- Percentage of hypochromic red blood cells (HRC).

- Plasma/serum C-reactive protein (CRP) to assess inflammation.

Based on the initial assessment and in selected cases, the following tests may be useful to diagnose the cause of anaemia in some patients with CKD:

- Serum B12 and red cell folate concentrations.

- Tests for haemolysis (plasma/serum levels of haptoglobin, lactate dehydrogenase, bilirubin, Coombs' test).

- Plasma/serum and/or urine protein electrophoresis.

- Hb electrophoresis and bone marrow examination.

\section{Rationale}

Although relative erythropoietin deficiency is common among patients with anaemia and CKD, other potential causes should be identified or excluded.

Nephron Clin Pract 2011;118(suppl 1):c101-c124 
A clinical and laboratory evaluation of the cause of anaemia should precede initiation of ESA therapy. The recommended laboratory evaluation aims at assessing:

- The degree and cause of anaemia,

- Bone marrow responsiveness, and

- Iron stores and iron availability for erythropoiesis.

Anaemia due to causes other than erythropoietin deficiency should be suspected when:

- The severity of the anaemia is disproportionate to the deficit in renal function,

- There is evidence of iron deficiency,

- There is evidence of haemolysis, or

- There is evidence of bone marrow disorder as manifest by leucopaenia or thrombocytopaenia.

(a) Assessment of anaemia severity

In CKD patients not yet requiring dialysis and in those on peritoneal dialysis (PD), the timing of the blood sample draw is not critical because plasma volume in these patients remains relatively constant. In haemodialysis (HD) patients, interdialytic weight gain contributes to a decrease in $\mathrm{Hb}$ level, whereas intradialytic ultrafiltration leads to an increase in $\mathrm{Hb}$ level. Thus, a predialysis sample underestimates the euvolaemic $\mathrm{Hb}$ level, whereas a postdialysis sample over-estimates the euvolaemic Hb. In a study of 68 stable HD patients receiving recombinant human erythropoietin ( $\mathrm{rHuEPO})$ subcutaneously, average mean pre-dialysis $\mathrm{Hb}$ was 1 $\mathrm{gm} / \mathrm{dL}$ lower than average postdialysis $\mathrm{Hb}$ [21]. There was a strong linear inverse correlation between percentage of change in $\mathrm{Hb}$ and haematocrit $(\mathrm{Hct})$ values and percentage of change in body weight. In another study of 49 stable HD patients, among all pre-HD and post-HD $\mathrm{Hb}$ values, levels measured at the end of short dialysis intervals were closest to the mean $\mathrm{Hb}$ value of the week, derived from calculation of the area under the curve for the readings of the week [22]. Given the relationship between $\mathrm{Hb}$ level and the dialysis related weight change, midweek pre-dialysis sampling should be optimal for regular $\mathrm{Hb}$ monitoring.

(b) Assessment of Bone Marrow Responsiveness

In general, anaemia of CKD is normochromic and normocytic and is morphologically indistinguishable from the anaemia of chronic illness. Initial assessment of anaemia in CKD patients should aim at identifying other factors that may influence the response to treatment. In addition to $\mathrm{Hb}$, other indices of the $\mathrm{FBC}$ report may provide important clinical information:

- Macrocytosis could be due to folate or vitamin $B_{12}$ deficiency.

- In addition to anaemia of CKD, microcytosis could be due to iron deficiency or haemoglobinopathies.

- Macrocytosis with leucopaenia or thrombocytopaenia could be due to several factors such as alcohol intake, nutritional deficit (vitamin $\mathrm{B}_{12}$ or folate deficiency), or myelodysplasia.

- Haemolysis is suggested by the presence of macrocytosis, high lactate dehydrogenase and positive Coombs' test.

The normal absolute reticulocyte count ranges from 40,000 to 50,000 cells/L. Although it has a significant inter-patient variability, this test may be useful as a semi-quantitative marker of erythropoietic activity.

(c) Evaluating Iron Status in Anaemic Patients with CKD

The aim of evaluating iron status is to assess:

1. Iron level in tissue stores and

2. The adequacy of iron utilisation for erythropoiesis.

Serum ferritin level is the only available blood marker of storage iron. There are several tests to assess adequacy of iron for erythropoiesis: TSAT, MCV, $\mathrm{MCH}$, percentage of hypochromic red blood cells (HRC) and reticulocyte $\mathrm{Hb}$ content $(\mathrm{CHr})$.

Tests limitations:

- HRC estimation is a useful test for assessment of iron availability but is limited by the effect of sample storage time and need for special analysers. Long sample storage time ( $>4$ hours) may spuriously increase HRC.

- MCV and $\mathrm{MCH}$ are decreased only after longstanding iron deficiency.

- TSAT is the most widely used test to assess the adequacy of iron supply for erythropoiesis but is limited by high day to day variations. TSAT is also influenced by nutritional status and inflammation.

- It is preferable to test $\mathrm{Hb}$, ferritin, and TSAT or $\mathrm{CHr}$ together because the combination provides an important insight into erythropoiesis, iron storage and iron availability to bone marrow.

In patients with CKD not on dialysis, serum ferritin levels less than $25 \mathrm{ng} / \mathrm{mL}$ in males and less than $12 \mathrm{ng} / \mathrm{mL}$ 
in females suggest depletion of iron stores as a cause of anaemia; but serum ferritin level is less reliable in the evaluation of iron stores in HD patients, because ferritin level is affected by other factors in addition to iron storage status. In relatively healthy HD patients, before widespread use of IV iron therapy, the finding of a ferritin level less than $50 \mathrm{ng} / \mathrm{mL}$ was not uncommon [23] and was associated with absent bone marrow iron in approximately $80 \%$ of patients [24]. However, in HD patients with several co-morbidities, absent iron stores may still be found at ferritin levels approaching or even exceeding $200 \mathrm{ng} / \mathrm{mL}$ [25].

Iron-deficiency erythropoiesis is most likely to contribute to anaemia when TSAT results are less than $16 \%$.
However, the clinical utility of TSAT is impaired by the absence of a diagnostic threshold, above which deficient iron utilisation can be excluded as a cause of anaemia [5]

There is little information in literature to guide the approach to CKD patients who show laboratory evidence of iron deficiency. Nevertheless, given the high prevalence of GI blood loss due to variety of causes in this patient population, deciding on a subsequent management plan, including endoscopy, depends on the clinical presentation. This supports the recommendation that CKD patients who present with anaemia and iron deficiency should undergo careful clinical assessment prior to the initiation of anaemia therapy [26-28].

\section{References}

1 Roger SD, McMahon LP, Clarkson A et al. Effects of early and late intervention with epoetin $\alpha$ on left ventricular mass among patients with chronic kidney disease (stage 3 or 4): Results of a randomized clinical trial. J Am Soc Nephrol 2004;15:148-156

$\checkmark 2$ Levin A, Djurdjev O, Thompson C et al. Canadian randomized trial of haemoglobin maintenance to prevent or delay left ventricular mass growth in patients with CKD. Am J Kidney Dis 2005;46:799-811

3 National Collaborating Centre for Chronic Conditions, Royal College of Physicians. Guideline on anaemia management in chronic kidney disease. 2006. National Institute for Clinical Excellence

4 Locatelli F, Aljama P, Barany P et al. Revised European Best Practice Guidelines for the management of anaemia in patients with chronic renal failure. Nephrol Dial Transplant 2004;19(Suppl 2):ii1-47

5 KDOQI; National Kidney Foundation Clinical practice guidelines and clinical practice recommendations for anemia in chronic kidney disease in adults. Am J Kidney Dis. 2006 May; 47(5 Suppl 3):S16-S85

6 www.kdigo.org

7 World Health Organisation. Iron deficiency anaemia, assessment, prevention and control: a guide for programme managers. 2001

$>8$ Beall CM, Goldstein MC. Hemoglobin concentration of pastoral nomads permanently resident at 4,850-5,450 meters in Tibet. Am J Phys Anthropol 1987;73:433-438

9 http://www.renal.org/eGFRcalc/GFR.pl

10 Cheng CK, Chan J, Cembrowski GS, van Assendelft OW. Complete blood count reference interval diagrams derived from NHANES III: stratification by age, sex, and race. Lab Hematol 2004;10:42-53

$\checkmark 11$ de Lusignan S, Chan T, Stevens $\mathrm{P}$ et al. Identifying patients with chronic kidney disease from general practice computer records. Fam Pract 2005;22:234-241

12 Guralnik JM, Eisenstaedt RS, Ferrucci L, Klein HG, Woodman RC. Prevalence of anaemia in persons 65 years and older in the United States: Evidence for a high rate of unexplained anemia. Blood 2004;104:2263-2268

13 Ishimura E, Nishizawa Y, Okuno S et al. Diabetes mellitus increases the severity of anaemia in non-dialyzed patients with renal failure. J Nephrol 1998;11:83-86

- 14 Bosman DR, Winkler AS, Marsden JT, Macdougall IC, Watkins PJ. Anaemia with erythropoietin deficiency occurs early in diabetic nephropathy. Diabetes Care 2001;24:495-499

15 Thomas MC, MacIsaac RJ, Tsalamandris C, Power D, Jerums G. Unrecognised anaemia in patients with diabetes: A cross-sectional survey. Diabetes Care 2003;26:1164-1169
16 Thomas MC, MacIsaac RJ, Tsalamandris C et al. The burden of anaemia in type 2 diabetes and the role of nephropathy: A cross-sectional audit. Nephrol Dial Transplant 2004;19:1792-1797

17 El-Achkar TM, Ohmit SE, McCullough PA et al. Higher prevalence of anaemia with diabetes mellitus in moderate kidney insufficiency: The Kidney Early Evaluation Program. Kidney Int 2005;67:1483-1488

18 Erslev AJ, Besarab A. The rate and control of baseline red cell production in hematologically stable patients with uremia. J Lab Clin Med 1995; 126(3):283-286

19 Naets JP, Garcia JF, Tousaaint C, Buset M, Waks D. Radioimmunoassay of erythropoietin in chronic uraemia or anephric patients. Scand J Haematol 1986;37:390-394

20 Ross RP, McCrea JB, Besarab A. Erythropoietin response to blood loss in haemodialysis patients in blunted but preserved. ASAIO J 1994;40: M880-M885

21 Movilli E, Pertica N, Camerini C et al. Predialysis versus postdialysis hematocrit evaluation during erythropoietin therapy. Am J Kidney Dis 2002;39:850-853

22 Bellizzi V, Minutolo R, Terracciano V et al. Influence of the cyclic variation of hydration status on haemoglobin levels in hemodialysis patients. Am J Kidney Dis 2002;40:549-555

23 Fishbane S, Lynn RI. The efficacy of iron dextran for the treatment of iron deficiency in hemodialysis patients. Clin Nephrol 1995;44:238-240

24 Fernandez-Rodriguez AM, Guindeo-Casasus MC, Molero-Labarta T et al. Diagnosis of iron deficiency in chronic renal failure. Am J Kidney Dis 1999;34:508-513

25 Kalantar-Zadeh K, Hoffken B, Wunsch H, Fink H, Kleiner M, Luft FC. Diagnosis of iron deficiency anemia in renal failure patients during the post-erythropoietin era. Am J Kidney Dis 1995;26:292-299

26 Coban E, Timuragaoglu A, Meric M. Iron deficiency anemia in the elderly: Prevalence and endoscopic evaluation of the gastrointestinal tract in outpatients. Acta Haematol 2003;110:25-28

27 Ioannou GN, Rockey DC, Bryson CL, Weiss NS. Iron deficiency and gastrointestinal malignancy: A population-based cohort study. Am J Med 2002;113:276-280

28 Ioannou GN, Spector J, Scott K, Rockey DC. Prospective evaluation of a clinical guideline for the diagnosis and management of iron deficiency anemia. Am J Med 2002;113:281-287 


\section{Anaemia of CKD (Guidelines 2.1-2.10)}

\section{Guideline 2.1 - Treatment of Anaemia -}

\section{Erythropoiesis Stimulating Agents}

We recommend that treatment with Erythropoiesis Stimulating Agents (ESAs) should be offered to patients with anaemia of CKD who are likely to benefit in terms of quality of life and physical function and to avoid transfusion in patients considered suitable for transplantation. (1A)

\section{Audit measure}

Proportion of patients on renal replacement therapy with $\mathrm{Hb}$ level $<10 \mathrm{~g} / \mathrm{dL}$ who are not prescribed an ESA

\section{Rationale}

Treatment of anaemia in CKD with ESA can be expensive [1], takes time to work and carries a small but significant risk to the patient. It is therefore reasonable, as with any therapy, to treat only those who are expected to benefit in the timeframe that therapy is being considered. For example, patients with severe sepsis/ inflammation/acute bleeding are unlikely to respond. Patients with a very short life expectancy (days or weeks) are not likely to survive long enough for therapy to provide benefit in terms of an increase in $\mathrm{Hb}$. The clinician and patient should agree on a therapeutic plan and, at an appropriate time, review whether therapy is providing enough benefit to continue treatment.

\section{Guideline 2.2 - Treatment of Anaemia - Choice of ESA}

We recommend that the decision on the choice of ESA is based on local availability of ESAs. (1B)

\section{Audit measure}

Each renal unit should audit the type, route and frequency of administration and weekly dose of ESA prescribed

\section{Rationale}

Many studies have been published comparing different ESA products against each other when used at different dosing intervals, by different routes of administration and in different patient groups. All the available products are efficacious when administered according to the manufacturers' recommendations. The choice of ESA will be dependent upon the clinician and patient agreeing a management plan and local supply arrangements [1].
Guideline 2.3 - Treatment of Anaemia with ESA therapy - Target $\mathrm{Hb}$

We recommend that patients with CKD on ESA therapy should achieve $\mathrm{Hb}$ between 10-12 g/dl. (1B)

Guideline 2.4 - Treatment of Anaemia without ESA therapy - Target $\mathrm{Hb}$

We recommend that these $\mathrm{Hb}$ targets apply exclusively to patients receiving ESA and are not intended to apply to the treatment of iron deficiency in patients receiving iron therapy without the use of ESAs. (1B)

\section{Audit measures}

The proportion of CKD stage 4-5 patients with $\mathrm{Hb}$ $10-12 \mathrm{~g} / \mathrm{dl}$

The proportion of patients treated with an ESA with $\mathrm{Hb}>12 \mathrm{~g} / \mathrm{dl}$

\section{Rationale for Guidelines 2.3 and 2.4}

- In determining target $\mathrm{Hb}$ guidelines it is important to assess potential benefits (in terms of possible improved survival, improvement in health related quality of life - HRQoL - and avoidance of transfusion) vs. potential harms (increased mortality, increased risk of vascular events).

- Although several studies have shown that higher $\mathrm{Hb}$ targets lead to improvements in both physical and mental health domains [2-5] the HRQoL benefits of higher $\mathrm{Hb}$ targets diminish over time $[3,6]$. In addition, there is no apparent $\mathrm{Hb}$ threshold above which there is definitively a quality-of-life improvement in the higher $\mathrm{Hb}$ treatment arms.

- Recently the Anaemia Working Group of ERBP expressed its view that $\mathrm{Hb}$ values of $11-12 \mathrm{~g} / \mathrm{dL}$ should be generally sought in the CKD population without intentionally exceeding $13 \mathrm{~g} / \mathrm{dL}$ [7].

- The rationale behind choosing a wide target $\mathrm{Hb}$ range $(10-12 \mathrm{~g} / \mathrm{dl})$ is that when the target $\mathrm{Hb}$ level is narrow (i.e. $1 \mathrm{~g} / \mathrm{dL}$ ), variability in achieved $\mathrm{Hb}$ levels around the target is high, the fraction of prevalent patients with achieved $\mathrm{Hb}$ levels within the target range is low and ESA dose titration is required frequently during maintenance therapy [8].

- The health economics of anaemia therapy using ESAs has been subject to a NICE systematic review [1] which concludes that treating to a target $\mathrm{Hb}$ $11-12 \mathrm{~g} / \mathrm{dl}$ is cost effective in HD patients. In a US study the incremental cost per quality-adjusted life year (QALY) of target $\mathrm{Hb} 12.0-12.5 \mathrm{~g} / \mathrm{dl}$ vs. 11.0 $12.0 \mathrm{~g} / \mathrm{dl}$ was $\$ 613,015$. An additional $\$ 828,215$ per 
Table 1. $\mathrm{Hb}$ data for UK prevalent $\mathrm{HD}$ patients $[9,10]$

\begin{tabular}{cccccc}
\hline & $\mathrm{Hb}($ Mean $\pm \mathrm{sd})$ & $\mathrm{Hb}>10 \mathrm{~g} / \mathrm{dl}$ & $90 \% \mathrm{Hb}$ range & Interquartile $\mathrm{Hb}$ range & $\mathrm{Hb}>11 \mathrm{~g} / \mathrm{dl}$ \\
\hline 2005 & $11.7 \pm 1.6$ & $85 \%$ & $9.2-14.6$ & $10.6-12.8$ & $68 \%$ \\
2008 & $11.6 \pm 1.5$ & $86 \%$ & $8.9-14$ & $10.6-12.6$ & $68 \%$ \\
\hline
\end{tabular}

additional QALY gained was required to achieve a target $\mathrm{Hb}$ of $14 \mathrm{~g} / \mathrm{dl}$ versus $12.0-12.5 \mathrm{~g} / \mathrm{dl}$. To put this guideline into current context, Table 1 summarises the mean $\mathrm{Hb}$ data for prevalent UK dialysis patients from the Eighth (2005) and Eleventh (2008) UK Renal Registry Reports [9, 10].

- Besarab et al. [5] reported a study of normalisation of haemoglobin in patients with high cardiovascular risk on haemodialysis. Normalisation of haemoglobin showed no benefit in risk reduction but did show an improvement in quality of life. The treatment arm showed a trend towards increased risk of death and vascular access failure and the trial was stopped on the grounds that the study was unlikely to show benefit from normalisation.

- There have been two important studies of patients not yet on dialysis - CHOIR [11] and CREATE [2]. The outcome of the CHOIR study showed no benefit of higher haemoglobin outcome in CKD patients randomised to $\mathrm{Hb}$ of $11.3 \mathrm{~g} / \mathrm{dl}$ vs. $13.5 \mathrm{~g} /$ dl. Higher outcome target $\mathrm{Hb}$ had an increased risk (using composite end-points of death, myocardial infarction, or hospitalisation for congestive cardiac failure) and no incremental improvement in quality of life. The limitation of this study is that, compared with the group assigned to the lower $\mathrm{Hb}$ treatment target, the higher $\mathrm{Hb}$ target group showed at baseline a statistically greater proportion of patients with a history of hypertension and coronary artery bypass graft. A report posted by the study sponsor (PROCRIT ${ }^{\circledR}$ : Clinical Study Report PR00-06-014 (CHOIR) Synopsis, 12 September 2006; available at: www.clinicaltrials.gov, last accessed January 12, 2007) indicates that patients assigned to the higher $\mathrm{Hb}$ treatment arm also had a significantly greater severity of congestive heart failure (CHF) at baseline. The results of a multivariate analysis, included in this report, indicate that after adjustment for baseline conditions (CHF by National Health and Nutrition Examination Survey CHF score, atrial fibrillation/flutter, serum albumin level, reticulocyte count, and age), the relationship between treatment assignment and primary composite outcome events is no longer statistically significant (hazard ratio [HR], $1.24 ; 95 \%$ confidence interval $[\mathrm{CI}], 0.95$ to 1.62 ; $\mathrm{p}=0.11$ compared with the unadjusted $\mathrm{HR}$ of $1.34 ; 95 \% \mathrm{CI}, 1.03$ to $1.74 ; \mathrm{p}=0.03$ reported in the publication [11]). A secondary analysis of the CHOIR trial suggested that higher doses of epoetin $\alpha$ were associated with an increased risk of death, myocardial infarction, congestive heart failure or stroke compared with lower epoetin doses, and with poorer outcomes [12]. Another secondary analysis of the CHOIR study found that, among patients with diabetes mellitus, the percentage of patients reaching the primary end point of death, myocardial infarction, congestive heart failure or stroke within 3 years was similar in the high and low haemoglobin arms of the trial $(24.8 \%$ versus $24.7 \%$, respectively; $\mathrm{p}=0.249$ ). By contrast, among patients without diabetes mellitus at baseline, $36.4 \%$ of patients randomised to the higher haemoglobin target had reached the primary end point after 3 years compared with $24 \%$ of those randomised to the lower haemoglobin target (HR 1.70; 95\% CI 1.03-2.81; $\mathrm{p}=0.04)$. In other words, individuals without diabetes mellitus randomised to the higher haemoglobin target had a significantly greater risk of reaching the primary end point after 3 years than individuals with diabetes mellitus randomised to the lower haemoglobin target [13].

- The CREATE [2] study reported that early correction of anaemia to normal $\mathrm{Hb}(13-15 \mathrm{~g} / \mathrm{dl}$ vs. $10.5-11.5 \mathrm{~g} / \mathrm{dl}$ ) did not reduce risk of cardiovascular events. Indeed the hazards ratio for primary endpoints of death from any cause or death from cardiovascular disease consistently (but not significantly) favoured the lower haemoglobin target group. The trend to increase in events appeared to occur after initiation of dialysis but there was no difference in endpoints after censoring of data from patients who started dialysis. Quality of life was significantly better in the higher $\mathrm{Hb}$ outcome group. Although GFR was not significantly different between the two groups, more patients started renal replacement 
therapy earlier in the higher $\mathrm{Hb}$ outcome group $(\mathrm{p}=0.03)$ with the difference apparent from 18 months. An important limitation of this trial is that the event rate was much lower than predicted; thus, the power to detect a difference in event rates was decreased.

- Other important limitation(s) of these trials is the lack of assessment of $\mathrm{Hb}$ cycling around each target $\mathrm{Hb}$. In addition, important subgroups of patients enrolled in large trials, such as young adults, patients returning to dialysis after failed renal transplant, or patients with chronic lung disease were not identified or assessed in any of these trials.

- Further analysis of outcome of high target $\mathrm{Hb}$ was performed by the KDOQI team. An Evidence Review Team analysed all data from randomised controlled trials of anaemia management in CKD, including, CHOIR [11], CREATE [2] and other studies. Combining mortality outcomes from eight studies involving 3038 subjects with CKD who were not on dialysis (the CHOIR and CREATE studies contributed most of the weight to the analysis) revealed no difference between the higher and lower $\mathrm{Hb}$ target [14], but combining adverse cardiovascular events from six studies involving 2850 subjects showed an increased risk among the patients assigned to the higher $\mathrm{Hb}$ targets (a RR of 1.24, 95\% CI 1.021.51) [14], although it is worth noting that the CHOIR and CREATE studies contributed most of the weight to the analysis. Among dialysis patients, combining mortality (four studies, 2391 subjects) or cardiovascular outcomes (three studies, 1975 subjects) showed no statistically significant difference between the higher and lower $\mathrm{Hb}$ level with $\mathrm{The} \mathrm{Hb}$ Normalisation Study [5] contributing most of the weight to the analysis.

- In the TREAT study [15], 4038 patients with diabetes, chronic kidney disease not on dialysis, and anaemia, were randomly assigned in a 1:1 ratio to darbepoetin $\alpha$, to achieve a haemoglobin level of approximately $13 \mathrm{~g} / \mathrm{dL}$ or to placebo, with rescue darbepoetin $\alpha$ when the haemoglobin level was less than $9.0 \mathrm{~g} / \mathrm{dL}$. The primary end points were the composite outcomes of death or a cardiovascular event (nonfatal myocardial infarction, congestive heart failure, stroke, or hospitalisation for myocardial ischemia) and of death or end-stage renal disease. After a median follow up of 29 months, there was no difference between the two arms in the primary outcome of death, cardiovascular event or end stage renal disease. Fatal or nonfatal stroke occurred in 101 patients assigned to darbepoetin $\alpha$ and 53 patients assigned to placebo ( $\mathrm{HR}, 1.92 ; 95 \% \mathrm{CI}$, 1.38 to $2.68 ; \mathrm{p}<0.001)$. The investigators concluded that for many involved in clinical decision making this risk of prescribing an ESA in this patient population will outweigh the potential benefits [15].

- Data from observational studies have, however, not shown increased hazard risk among patients who achieved higher haemoglobin. In one study, data from haemodialysis patients in the UK Renal Registry from 1999 to 2005 were analysed for the relative risk of death at different haemoglobin concentrations. Haemoglobin concentrations above the reference range $(10-11 \mathrm{~g} / \mathrm{dl})$ consistently showed a $35 \%$ lower relative risk of death, while patients with haemoglobin below $10 \mathrm{~g} / \mathrm{dl}$ had a $28 \%$ higher mortality. The greatest mortality was seen in patients with haemoglobin $<9 \mathrm{~g} / \mathrm{dl}$ ( $73 \%$ increased risk of death, although due to the small numbers, this was not statistically significant). On the other hand, the lowest death rate was seen in patients with haemoglobin levels between 12 and $13 \mathrm{~g} / \mathrm{dl}$ (64\% reduced mortality) [16].

- The effect of cumulative ESA dose was also reported in another retrospective study [17]. In this study, which looked at data from Medicare's end-stage renal disease program between 1999 and 2007, different US dialysis centres' annual anaemia management practice were characterised by estimating their typical use of ESAs and intravenous iron in haemodialysis patients within 4 hematocrit categories. Monthly mortality rates were assessed using Cox proportional hazards regression to correlate centre-level patterns of ESA and iron use with 1-year mortality risk in 269,717 incident haemodialysis patients. Monthly mortality rates were highest in patients with haematocrit less than 30\% (mortality, 2.1\%) and lowest for those with haematocrit of $36 \%$ or higher (mortality, $0.7 \%)$. After adjustment for baseline case-mix differences, dialysis centres that used larger ESA doses in patients with haematocrit less than 30\% had lower mortality rates than centres that used smaller doses (highest vs. lowest dose group: HR, 0.94; 95\% CI, 0.90-0.97). Centres that administered iron more frequently to patients with haematocrit less than 33\% also had lower mortality rates (highest vs. lowest quintile, HR, 0.95; 95\% CI, 0.910.98). However, centres that used larger ESA doses 
in patients with haematocrit between $33 \%$ and $35.9 \%$ had higher mortality rates (highest vs. lowest quintile, HR, 1.07; 95\% CI, 1.03-1.12). More intensive use of both ESAs and iron was associated with increased mortality risk in patients with haematocrit of $36 \%$ or higher [17].

Despite the limitation(s) of each trial, these studies support the current haemoglobin outcome recommendations in this document and the NICE update recommendations on management of anaemia in patients with chronic kidney disease [8].

\section{Guideline 2.5 - Treatment of Anaemia - Initial ESA} dose

We recommend that the initial ESA dose should be determined by the patient's $\mathrm{Hb}$ level, the target $\mathrm{Hb}$ level, the observed rate of increase in $\mathrm{Hb}$ level and clinical circumstances. (1B)

\section{Rationale}

For initiation of ESA therapy, several points are to be considered:

- Type(s) of licensed ESAs available

- Initial ESA dose

- ESA dose adjustment: dose required for $\mathrm{Hb}$ correction vs. maintenance

- Route of ESA administration

- Frequency of ESA administration that best fit patient requirements and achieve maximal convenience

- Patient monitoring for the anticipated response in terms of $\mathrm{Hb}$ rise, rate of $\mathrm{Hb}$ rise, possible adverse effect (e.g. hypertension).

In general, the aim of initial ESA therapy is to achieve a rate of increase in $\mathrm{Hb}$ levels of 1 to $2 \mathrm{~g} / \mathrm{dL}$ per month. This rate of rise is considered safe as evidenced from interventional trials on ESA naïve patients [18-20]. In $\mathrm{CKD}$ patients with initial $\mathrm{Hb}$ levels less than target range, these trials have shown the mean initial rate of $\mathrm{Hb}$ level increase to be in the range of 0.7 to $2.5 \mathrm{~g} / \mathrm{dL}$ in the first 4 weeks. This rate of $\mathrm{Hb}$ increase is affected by the patient population, initial ESA dose, and the frequency and route of ESA administration.

\section{Guideline 2.6 - Treatment of Anaemia with ESA therapy - Route of administration}

We suggest that the route of ESA administration should be determined by the CKD stage, treatment setting, efficacy, safety, and class of ESA used; subcutaneous (SC) route is the access of choice in non-HD patients, while convenience may favour intravenous (IV) administration in $\mathrm{HD}$ patients. (2B)

\section{Audit measure}

Each renal unit should audit the type, route and frequency of administration and weekly dose of ESA prescribed

\section{Rationale}

In the outpatient setting, SC administration is the only routinely feasible route of administration for non HD CKD patients. For HD patients, either SC or IV administration is feasible.

Among short-acting ESAs, subcutaneous administration is associated with approximately $30 \%$ reduction in dose requirements compared to that of IV administration for the same target $\mathrm{Hb}$ outcome. This has been proven in a large multicenter RCT on long term HD patients who had their haematocrit maintained within target range while on epoetin $\alpha$ either via SC or IV route. Patients were then randomised to IV or SC route. Upon randomisation, ESA doses were first decreased to allow haematocrit levels to decrease to less than target range. Doses were titrated upward to again achieve target haematocrit levels, and then were adjusted to maintain haematocrit in the target range during a 26-week maintenance phase. Among 107 patients who completed the trial, those assigned to SC route showed 27\% lower ESA doses than those assigned to IV administration [21]. However, not all patients showed a dose decrease after conversion from IV to SC, and some patients showed a dose increase.

Among long-acting agents, efficacy of SC administration appears to be equivalent to that of IV route at the examined dosing frequencies [22-25].

\section{Guideline 2.7 - Treatment of Anaemia with ESA therapy - Frequency of administration}

We suggest that the frequency of administration should be determined by the CKD stage, treatment setting and class of ESA. Less frequent administration using long acting ESAs may be the treatment of choice in non-HD patients. (2B)

\section{Rationale}

The frequency of ESA administration should be determined by the CKD treatment setting and the class of ESA. Maximum efficacy is achieved by using the dosing intervals that are ESA class specific. In HD 
patients receiving SC short-acting ESA therapy, ESA efficacy is maximal when the drug is given thrice weekly. ESA efficacy decreases and dose requirement increases when the dosing frequency is extended from thriceweekly to once-weekly administration [26]. Increasing the time interval between dosages of long acting ESAs could also result in an increase in dose requirements [27].

\section{Guideline 2.8 - Treatment of Anaemia with ESA Therapy - ESA dose adjustments}

We recommend that adjustments to ESA doses should be considered when $\mathrm{Hb}$ is $<10.5$ or $>11.5 \mathrm{~g} / \mathrm{dL}$ in order to balance benefit and safety to patients given the current evidence base. These thresholds for intervention should achieve a population distribution centred on a mean of $11 \mathrm{~g} / \mathrm{dl}$ with a range of $10-12 .(1 \mathrm{~B})$

\section{Guideline 2.9 - Treatment of Anaemia with ESA Therapy - ESA dose adjustments}

We suggest that ESA doses should ideally be decreased rather than withheld when a downward adjustment of $\mathrm{Hb}$ level is needed. (2B)

\section{Guideline 2.10 - Treatment of Anaemia with ESA}

\section{Therapy}

We recommend that ESA administration in ESAdependent patients should continue during acute illness, surgical procedures or any other cause of hospitalisation. (1B)

\section{Audit measure}

Each renal unit should monitor ESA dose adjustments

\section{Rationale for Guidelines 2.8-2.10}

- It is acknowledged that in a dialysis population the $\mathrm{Hb}$ distribution results in the majority of $\mathrm{Hb}$ values not lying within the range 11-12 g/dL $[1,9,28]$. The updated NICE Guidelines for anaemia management in chronic kidney disease [8] recommend an outcome $\mathrm{Hb}$ of $10-12$. It is anticipated that if a population $\mathrm{Hb}$ distribution is centred on this outcome with a mean of $11 \mathrm{~g} / \mathrm{dl}$, then $85 \%$ of the population will have $\mathrm{Hb}>10.0 \mathrm{~g} / \mathrm{dl}$.

- In HD patients, withholding ESA doses for $\mathrm{Hb}$ levels greater than the target range is associated with subsequent downward $\mathrm{Hb}$ excursions often to levels less than target range [29]. The time between withholding ESA doses and return of $\mathrm{Hb}$ to target range is variable and unpredictable. In
$\mathrm{HD}$ patients with $\mathrm{Hb}$ values greater than $14.0 \mathrm{~g} /$ $\mathrm{dL}$, the median time for $\mathrm{Hb}$ to return to $12.0 \mathrm{~g} / \mathrm{dL}$ or less after withholding of a SC-administered ESA is 7-9 weeks. The difference between withholding long and short acting ESAs on the rate of $\mathrm{Hb}$ reduction is not significant [20].

- Either 10-16\% ESA dose changes [30] or up to $25 \%$ dose changes [26] can be equally effective maintenance dose-titration strategies. This was shown in two separate studies. The first was a computerassisted support decision system algorithm that had been tested in a 24 month prospective study on chronic HD patients on SC epoetin $\alpha$. In this study, the monthly dose of epoetin was adjusted according to monthly $\mathrm{Hb}$ level using lower and upper $\mathrm{Hb}$ thresholds beyond which the ESA dose was increased or decreased respectively. The average dose change was $10-16 \%$ of baseline ESA dose. $\mathrm{Hb}$ outcome was maintained with medians between 11.3 and $11.8 \mathrm{~g} / \mathrm{dL}$, and a median epoetin $\alpha$ dose reduction from 136 to $72 \mathrm{IU} / \mathrm{kg} /$ week. The second study examined the effect of initiating a fixed monthly downward ESA dose adjustment in response to monthly $\mathrm{Hb}$ levels $>13.0 \mathrm{~g} / \mathrm{dL}$. The study examined a large database containing 95,000 HD patients on epoetin therapy [29]. At baseline approximately $35 \%$ patients showed average 3month $\mathrm{Hb}$ results within the target range of 11 to $12 \mathrm{~g} / \mathrm{dL}$, and $15 \%$ showed average 3-month $\mathrm{Hb}$ results greater than $13.0 \mathrm{~g} / \mathrm{dL}$. When a computermandated 25\% monthly dose decrease was initiated for end-of month $\mathrm{Hb}$ results greater than $13.0 \mathrm{~g} / \mathrm{dL}$, the mean $\mathrm{Hb}$ level did not change, but the percentage of patients with $\mathrm{Hb}$ values greater than $13.0 \mathrm{~g} / \mathrm{dL}$ increased and the percentage of patients with $\mathrm{Hb}$ values $<11 \mathrm{~g} / \mathrm{dL}$ increased.

- ESA dose adjustment may be higher during initiation (or titration after switch between different ESAs) than maintenance phases of ESA therapy. In a randomised double blind trial comparing a short-acting ESA with a long-acting ESA in haemodialysis patients previously receiving epoetin $\alpha$, dose adjustments were made in $25 \%$ increments or decrements of the baseline dose, aiming to maintain individual $\mathrm{Hb}$ concentrations within a range of 9.0 to $13.0 \mathrm{~g} / \mathrm{dL}$ [30]. Approximately $70 \%$ of patients required dose adjustment in the 20week titration period, and 50\% required dose adjustment during the 8 week maintenance period. 


\section{References}

1 National Collaborating Centre for Chronic Conditions, Royal College of Physicians. Guideline on anaemia management in chronic kidney disease. 2006. National Institute for Clinical Excellence

2 Drueke TB, Locatelli F, Clyne N et al. Normalisation of hemoglobin level in patients with chronic kidney disease and anemia. N Engl J Med 2006;355:2071-2084

$\checkmark 3$ Furuland H, Linde T, Ahlmen J et al. A randomized controlled trial of haemoglobin normalisation with epoetin $\alpha$ in pre-dialysis and dialysis patients. Nephrol Dial Transplant 2003;18:353-361

$\checkmark 4$ Foley RN, Parfrey PS, Morgan J et al. Effect of hemoglobin levels in hemodialysis patients with asymptomatic cardiomyopathy. Kidney Int 2000;58:1325-1335

5 Besarab A, Bolton WK, Browne JK et al. The effects of normal as compared with low hematocrit values in patients with cardiac disease who are receiving hemodialysis and epoetin. N Engl J Med 1998;339:584-590

6 Parfrey PS, Foley RN, Wittreich BH et al. Double blind comparison of full and partial anemia correction in incident hemodialysis patients without symptomatic heart disease. JAm Soc Nephrol 2005;16:21802189

7 Locatelli F, Aljama P, Canaud B, Covic A, De Francisco A, Macdougall IC, Wiecek A, Vanholder R. Anaemia Working Group of European Renal Best Practice (ERBP). Target haemoglobin to aim for with erythropoiesis-stimulating agents: a position statement by ERBP following publication of the Trial to Reduce cardiovascular Events with Aranesp Therapy (TREAT) study. Nephrol Dial Transplant. 2010; Sept 25(9):2846-2850

8 http://www.nice.org.uk/nicemedia/live/12958/50986/50986.pdf

9 UK Renal Registry. UK Renal Registry Report: The Eighth Annual Report. 8. 2005.http://www.renalreg.com/Report-Area/Report\%202005/chap-08.pdf (last accessed 17/11/09)

10 UK Renal Registry. UK Renal Registry Report: The Eleventh Annual Report. 11. 2008.http://www.renalreg.com/Report-Area/Report\%202008/ Chapter09.pdf (last accessed 17/11/09)

11 Singh AK, Szczech L, Tang KL et al. Correction of anemia with epoetin $\alpha$ in chronic kidney disease. N Eng J Med 2006;355:20 2085-2098

-12 Szczech LA, Barnhart HX, Inrig JK, Reddan DN, Sapp S, Califf RM, Patel UD, Singh AK. Secondary analysis of the CHOIR trial epoetin $\alpha$ dose and achieved hemoglobin outcomes. Kidney Int. 2008;74(6): 791-798

13 Szczech LA, Barnhart HX, Sapp S, Felker GM, Hernandez A, Reddan D, Califf RM, Inrig JK, Patel UD, Singh AK. A secondary analysis of the CHOIR trial shows that comorbid conditions differentially affect outcomes during anaemia treatment. Kidney Int. 2010;77(3):239-246

14 KDOQI clinical practice guideline and clinical practice recommendations for anemia in chronic kidney disease, 2007 update of haemoglobin target. Am J Kidney Dis 2007;50(3):471-530

15 Pfeffer et al. A Trial of Darbepoetin $\alpha$ in Type 2 Diabetes and Chronic Kidney Disease N Engl J Med 2009;361:2019-2032

-16 Macdougall IC, Tomson CR, Steenkamp M, Ansell D. Relative risk of death in UK haemodialysis patients in relation to achieved haemoglobin from 1999 to 2005: an observational study using UK Renal Registry data incorporating 30,040 patient-years of follow-up. Nephrol Dial Transplant. 2010;25(3):914-919
17 Brookhart MA, Schneeweiss S, Avorn J, Bradbury BD, Liu J, Winkelmayer WC. Comparative mortality risk of anemia management practices in incident hemodialysis patients. JAMA. 2010;303(9):857-864

18 Eschbach JW, Abdulhadi MH, Browne JK et al. Recombinant human erythropoietin in anemic patients with end-stage renal disease. Results of a phase III multicenter clinical trial. Ann Intern Med 1989;111: 992-1000

19 Eschbach JW, Kelly MR, Haley NR, Abels RI, Adamson JW. Treatment of the anemia of progressive renal failure with recombinant human erythropoietin. N Engl J Med 1989;321:158-163

20 Locatelli F, Olivares J, Walker R et al. Novel erythropoiesis stimulating protein for treatment of anemia in chronic renal insufficiency. Kidney Int 2001;60:741-747

21 Kaufman JS, Reda DJ, Fye CL et al. Subcutaneous compared with intravenous epoetin in patients receiving hemodialysis. Department of Veterans Affairs Cooperative Study Group on Erythropoietin in Hemodialysis Patients. N Engl J Med 1998;339:578-583

22 Locatelli F, Canaud B, Giacardy F, Martin-Malo A, Baker N, Wilson J. Treatment of anaemia in dialysis patients with unit dosing of darbepoetin $\alpha$ at a reduced dose frequency relative to recombinant human erythropoietin (rHuEpo). Nephrol Dial Transplant 2003;18:362-369

23 Vanrenterghem Y, Barany P, Mann JF et al. Randomized trial of darbepoetin $\alpha$ for treatment of renal anemia at a reduced dose frequency compared with $\mathrm{rHuEPO}$ in dialysis patients. Kidney Int 2002;62:2167-2175

24 Spinowitz B, Coyne DW, Lok CE, Fraticelli M, Azer M, Dalal S, Villa G, Rosansky S, Adamis H, Beyer U. RUBRA Study Investigators: C.E.R.A. maintains stable control of hemoglobin in patients with chronic kidney disease on dialysis when administered once every two weeks. Am J Nephrol 2008;28(2):280-289

25 Klinger M, Arias M, Vargemezis V, Besarab A, Sulowicz W, Gerntholtz T, Ciechanowski K, Dougherty FC, Beyer U. Efficacy of intravenous methoxy polyethylene glycol-epoetin beta administered every 2 weeks compared with epoetin administered 3 times weekly in patients treated by hemodialysis or peritoneal dialysis: a randomized trial. Am J Kidney Dis 2007;50(6):989-1000

26 Tolman C, Richardson D, Bartlett C, Will E. Structured conversion from thrice weekly to weekly erythropoietic regimens using a computerized decision-support system: A randomized clinical study. J Am Soc Nephrol 2005; 16:1463-1470

27 Jadoul M, Vanrenterghem Y, Foret M, Walker R, Gray SJ. Darbepoetin $\alpha$ administered once monthly maintains haemoglobin levels in stable dialysis patients. Nephrol Dial Transplant 2004;19:898-903

28 Richardson D, Bartlett C, Will EJ. Intervention thresholds and ceilings can determine the haemoglobin outcome distribution in a haemodialysis population. Nephrol Dial Transplant 2000;15: 2007-2013

29 Fishbane S, Berns JS. Hemoglobin cycling in hemodialysis patients treated with recombinant human erythropoietin. Kidney Int 2005;68: 1337-1343

30 Nissenson AR, Swan SK, Lindberg JS et al. Randomized, controlled trial of darbepoetin $\alpha$ for the treatment of anemia in hemodialysis patients. Am J Kidney Dis 2002;40:110-118 


\section{Anaemia of CKD (Guidelines 3.1-3.4)}

\section{Guideline 3.1 - Treatment of Anaemia with Iron therapy - Iron repletion}

We recommend that patients should be iron replete to achieve and maintain target $\mathrm{Hb}$ whether receiving ESAs or not. (1A)

\section{Rationale}

A definition of adequate iron status [1] is a serum ferritin

- 200-500 ng/L in HD patients,

- $100-500 \mathrm{ng} / \mathrm{ml}$ in non-HD patients and

- Either $<6 \%$ hypochromic red cells (HRC), or TSAT $>20 \%$.

The aim of iron treatment targets is to optimise anaemia therapy while minimising potential toxicity. Therapy targets aim at:

1. Minimising the ESA doses required to maintain target $\mathrm{Hb}$ levels in patients on ESA therapy and

2. Maximising the $\mathrm{Hb}$ level and minimising the need to initiate ESA therapy to achieve target-range $\mathrm{Hb}$ levels in patients not on ESA therapy.

Increasing the $\mathrm{Hb}$ in anaemic patients places the greatest demand for iron in the erythropoietic tissues. During ESA induction therapy iron requirements will depend on the rate of erythropoiesis, the $\mathrm{Hb}$ deficit, and ongoing iron loses. Once the target $\mathrm{Hb}$ has been reached and $\mathrm{Hb}$ stabilised, the iron requirements will be dependent on ongoing iron losses. When adequate iron status is achieved, CKD patients on ESA therapy should be given maintenance iron.

Several studies have reported that the dose of ESA required to achieve and maintain a given $\mathrm{Hb}$ outcome is inversely related to iron stores [2-7]. Iron deficiency (absolute or functional) was the main cause of ESA resistance in the UK but this has now been solved by iron replacement strategies [8]. In HD patient populations, the inverse relationship between ESA dose and iron stores continues to maintain a linear relationship up to a mean ferritin of $500 \mathrm{ng} / \mathrm{ml}$. Compliance with ferritin $>200$ predicts compliance of the RA minimum standard for $\mathrm{Hb}$ of $>85 \% \mathrm{Hb}$ values $>10.0 \mathrm{~g} / \mathrm{dL}$ [9]. The evidence behind the statement that TSAT generally should be maintained at greater than $20 \%$ stems from a single RCT comparing higher to lower TSAT targets; patients randomised to a target TSAT of $30 \%$ to $50 \%$ demonstrated a $40 \%$ reduction in ESA dose compared with those assigned to a target of $20 \%$ to $30 \%$ [10].

\section{Guideline 3.2 - Treatment of Anaemia with Iron therapy - Initiation of ESA and iron status}

We recommend that ESA therapy should not be initiated in the presence of absolute iron deficiency (ferritin $<100 \mathrm{ng} / \mathrm{ml}$ ). In patients with functional iron deficiency iron supplements should be given prior to or when initiating ESA therapy. (1A)

\section{Audit measure}

Proportion of patients with serum ferritin levels $<100 \mathrm{ng} / \mathrm{ml}$ at start of treatment with ESA

\section{Rationale}

Iron is a required for production of new red cells. Iron must be supplied to the erythropoietic tissue at an adequate rate, particularly if stimulated by ESA therapy. If iron stores are low ESAs can still be used if renal anaemia is a likely contributor to the anaemia as long as iron is made directly available to the erythropoietic tissues coincident with the initiation of ESA therapy [1].

\section{Guideline 3.3 - Treatment of Anaemia with Iron therapy - Route of Administration}

We suggest that oral iron will, in general, be sufficient to attain and maintain the $\mathrm{Hb}$ above targets in ESA treated CKD patients not yet requiring dialysis and in those on peritoneal dialysis (PD). (2B)

In contrast most $\mathrm{HD}$ patients will require intravenous iron. $(2 \mathrm{~A})$

\section{Audit measure}

Proportion of predialysis and PD patients receiving iron therapy; type: oral vs. parenteral

Proportion of HD patients receiving IV iron

\section{Rationale}

The evidence base for intravenous iron over oral iron in predialysis patients and PD patients is limited. Oral iron, if tolerated, appears to be adequate in most patients particularly in combination with ESA therapy. In patients who appear resistant to ESA therapy on oral iron, or are intolerant of oral iron, a therapeutic trial of IV iron trial seems reasonable. A study in predialysis patients and PD patients with functional iron deficiency despite oral iron therapy is needed. One randomised study of IV iron versus oral iron in predialysis patients 
demonstrated a greater improvement in $\mathrm{Hb}$ outcome in those on IV iron but no difference in the proportion of patients who had to commence ESA after the start of the study [11]. Two studies in predialysis patients not on ESA (one without oral iron and the other after oral iron therapy) demonstrated improvements in $\mathrm{Hb}$ outcome after IV iron $[12,13]$. Oral iron is easy and cheap to prescribe. It seems reasonable to treat patients who have not responded to or been intolerant of oral iron with IV iron.

Two randomised controlled studies of oral versus IV iron supplementation in predialysis patients receiving concomitant ESAs are in agreement. In the first study over a mean 5.2 months follow-up there was no difference in $\mathrm{Hb}$ or ESA dose between the oral and IV group receiving ESA [14]. Iron stores were greater in the IV than oral group. Similar findings appeared in a later study comparing 5 weeks of IV iron or 29 days of thrice daily oral iron. There was no difference in $\mathrm{Hb}$ or ESA dose but greater increase in ferritin in the IV group [15]. In PD patients a cross-over study of oral and IV iron demonstrated higher $\mathrm{Hb}$ and lower ESA doses after 4 months oral iron followed by a washout period and a single total dose of IV iron [16].

At present oral iron should remain first line treatment and IV iron used if patients are intolerant of oral iron or remain absolutely or functionally iron deficient despite oral iron. From the evidence to date IV iron is at least equivalent to oral iron therapy in efficacy and so can be administered to patients unable to take oral iron $[11,14]$.

HD patients have additional iron losses from GI bleeding, blood tests and losses in the dialysis lines that result in iron supplementation requirements that outstrip the capacity of the gut to absorb iron. Maintenance IV iron in HD patients greatly reduces ESA requirements and costs [10, 11, 17-20]. Maintaining iron stores/ maintaining a population ferritin outcome at steady state in a HD population requires $50-60 \mathrm{mg} /$ week of intravenous iron $[10,17,18]$. In PD patients and patients not on dialysis the evidence is not as strong. Hence for this patient population a lower ferritin of $100 \mathrm{ng} / \mathrm{ml}$ is quoted by NICE [1].

\section{Guideline 3.4 - Treatment of Anaemia with Iron therapy - Upper limit for iron therapy}

We recommend that serum ferritin should not exceed $800 \mathrm{ng} / \mathrm{ml}$ in patients treated with iron, and to achieve this iron management should be reviewed when the ferritin is $>500 \mathrm{ng} / \mathrm{ml}$. (1B)

\section{Rationale}

The UK Renal Registry Report 2005 [21] demonstrates that the proportion of individuals in a HD population with ferritin values $>100 \mathrm{ng} / \mathrm{ml}$ or $>200 \mathrm{ng} / \mathrm{ml}$ or indeed $>800 \mathrm{ng} / \mathrm{ml}$ is dependent on the median ferritin. As the distribution increases the compliance with values above minimum standards improves but the risk of breaching $800 \mathrm{ng} / \mathrm{ml}$ (and therefore risk of toxicity) also increases. At a median ferritin of $500 \mathrm{ng} / \mathrm{ml} \mathrm{5-25 \%}$ of individual patients may have a ferritin $>800 \mathrm{ng} / \mathrm{ml}$. The lower the standard deviation for ferritin, the lower will be the risk of a significant proportion of patients breaching $800 \mathrm{ng} / \mathrm{ml}$. Discontinuation of adequate maintenance IV iron when an individual's ferritin is $>500 \mathrm{ng} / \mathrm{ml}$ produces a population mean that straddles the $500 \mathrm{ng} / \mathrm{ml}$ ceiling [7]. Ongoing iron therapy in patients with ferritin $>500 \mathrm{ng} / \mathrm{ml}$ results in a higher median ferritin outcome [10].

Interpretation of iron status results and deciding on the need for further iron therapy should include a concomitant assessment of changes in $\mathrm{Hb}$ level and ESA dose over time. Examples:

- A dropping ferritin as well as decreasing $\mathrm{Hb}$ levels signifies blood loss e.g. on HD or bowel related: iron therapy is indicated; further investigation may be required depending on the clinical scenario.

- A decreasing ferritin level after initiation of ESA therapy, with a concomitant rise in $\mathrm{Hb}$ level indicates a response to ESA with a shift of iron from stores to bone marrow: further iron therapy is guided by target ferritin level.

- An increasing ferritin level after reduction of ESA dose to bring $\mathrm{Hb}$ level down to target range indicates ferritin level is rising as $\mathrm{Hb}$ synthesis is dropping: further iron therapy may be postponed.

- A rising ferritin level and a drop in TSAT suggest an inflammatory condition: a source of inflammation may be sought: sepsis, vascular access, surgery, recent hospitalisation: further iron therapy depends on target ferritin level and clinical scenario.

- Ongoing high requirements for IV iron to maintain a given ferritin level also point to ongoing blood loss.

The finding of a TSAT less than $20 \%$ coupled with a ferritin level greater than $500 \mathrm{ng} / \mathrm{mL}$ poses a particularly difficult problem for clinicians. This situation may be caused by iron test variability [22], inflammation, or reticuloendothelial iron blockade. Evidence on the risks 
and benefits of IV iron therapy in these patients is almost entirely lacking. The effect of iron therapy in this group of patients was assessed in The Dialysis patients' Response to IV iron with Elevated ferritin (DRIVE) trial [23], which evaluated the efficacy of intravenous ferric gluconate in 134 patients with high ferritin $(500-1200 \mathrm{ng} / \mathrm{ml})$ and low TSAT levels $(\leqslant 25 \%)$ who were anaemic despite a high $\mathrm{rHuEPO}$ dose $(\geqslant 225 \mathrm{IU} / \mathrm{kg} /$ week or $\geqslant 22,500 \mathrm{IU} /$ week). After 6 weeks the patients receiving ferric gluconate (125 mg IV at eight consecutive HD sessions) showed a significant increase in $\mathrm{Hb}$ in comparison with controls. However, the study has a number of limitations because, given the short follow-up, it provides no information about safety and iron overload.

\section{References}

1 National Collaborating Centre for Chronic Conditions, Royal College of Physicians. Guideline on anaemia management in chronic kidney disease. 2006. National Institute for Clinical Excellence

$\checkmark 2$ Besarab A, Amin N, Ahsan M et al. Optimisation of epoetin therapy with intravenous iron therapy in hemodialysis patients. J Am Soc Nephrol 2000;11:530-538

$\checkmark 3$ Besarab A, Dalton CL. Maintaining higher TSATs and other iron indices is beneficial in management of anemic hemodialysis patients. Nephrol Nurs J 2001;28:429-434

4 Coladonato JA, Frankenfield DL, Reddan DN et al. Trends in anemia management among US hemodialysis patients. J Am Soc Nephrol 2002;13:1288-1295

5 Kalantar-Zadeh K, McAllister CJ, Lehn RS et al. Effect of malnutritioninflammation complex syndrome on EPO hyporesponsiveness in maintenance hemodialysis patients. Am J Kidney Dis 2003;42:761-773

6 McClellan WM, Frankenfield DL, Wish JB et al. Subcutaneous erythropoietin results in lower dose and equivalent hematocrit levels among adult hemodialysis patients: Results from the 1998 End-Stage Renal Disease Core Indicators Project. Am J Kidney Dis 2001;37:E36

7 Richardson D, Bartlett C, Will EJ. Optimising erythropoietin therapy in hemodialysis patients. Am J Kidney Dis 2001;38:109-117

8 UK Renal Registry. UK Renal Registry Report: The Eighth Annual Report. 8. 2005

9 UK Renal Registry. UK Renal Registry Report: The Fifth Annual Report. UK, 2002

10 Besarab A, Amin N, Ahsan M et al. Optimisation of epoetin therapy with intravenous iron therapy in hemodialysis patients. J Am Soc Nephrol 2000;11:530-538

11 Van Wyck DB, Roppolo M, Martinez CO, Mazey RM, McMurray S. A randomized, controlled trial comparing IV iron sucrose to oral iron in anemic patients with nondialysis dependent CKD. Kidney Int 2005;68:2846-2856

-12 Anuradha S, Singh NP, Agarwal SK. Total dose infusion iron dextran therapy in predialysis chronic renal failure patients. Renal Failure 2002;24:307-313
$>1$ Silverberg DS, Iaina A, Peer G et al. Intravenous iron supplementation for the treatment of the anaemia of moderate to severe chronic renal failure patients not receiving dialysis. Am J Kidney Dis 1996;27:234-238

14 Stoves J, Inglis H, Newstead CG. A randomized study of oral vs. intravenous iron supplementation in patients with progressive renal insufficiency treated with erythropoietin. Nephrol Dial Transplant 2001;16:967-974

15 Charytan C, Qunibi W, Bailie GR. Comparison of intravenous iron sucrose to oral iron in the treatment of anemic patients with chronic kidney disease not on dialysis. Nephron Clin.Pract 2005;100:c55-c62

16 Ahsan N. Infusion of total dose iron versus oral iron supplementation in ambulatory peritoneal dialysis patients: a prospective, cross-over trial. Adv Perit Dial 2000;16:80-84

17 Besarab A, Kaiser JW, Frinak S. A study of parenteral iron regimens in hemodialysis patients. Am J Kidney Dis 1999;34:21-28

18 Macdougall IC, Chandler G, Elston O, Harchowal J. Beneficial effects of adopting an aggressive intravenous iron policy in a hemodialysis unit. Am J Kidney Dis 1999;34:S40-S46

19 Fishbane S, Frei GL, Maesaka J. Reduction in recombinant human erythropoietin doses by the use of chronic intravenous iron supplementation. Am J Kidney Dis 1995;26:41-46

20 Macdougall IC, Tucker B, Thompson J et al. A randomized controlled study of iron supplementation in patients treated with erythropoietin. Kidney Int 1996;50:1694-1699

21 UK Renal Registry. UK Renal Registry Report. The Eighth Annual Report. 2005

22 Fishbane S, Shapiro W, Dutka P, Valenzuela OF, Faubert J. A randomized trial of iron deficiency testing strategies in hemodialysis patients. Kidney Int 2001;60:2406-2411

23 Coyne DW, Kapoian T, Suki W et al. DRIVE Study Group. Ferric gluconate is highly efficacious in anemic hemodialysis patients with high serum ferritin and low transferrin saturation: results of the Dialysis Patients' Response to IV Iron with Elevated Ferritin (DRIVE) Study. J Am Soc Nephrol 2007;18:975-984 


\section{Anaemia of CKD (Guidelines 4.1-4.5)}

\section{Guideline 4.1 - Monitoring of treatment - Hb during ESA therapy}

We recommend that $\mathrm{Hb}$ concentration should be monitored every 2-4 weeks in the correction phase and every 1-3 months for stable patients in the maintenance phase. More frequent monitoring will depend on clinical circumstances. (1B)

\section{Rationale}

It is important to closely monitor $\mathrm{Hb}$ response to treatment to monitor for possible adverse events and plan ESA dose modification. More frequent $\mathrm{Hb}$ monitoring may be needed for patients with unstable $\mathrm{Hb}$, out of target $\mathrm{Hb}$ level, anticipated $\mathrm{Hb}$ drop due to blood loss/ haemolysis, infection or suboptimal dialysis.

The response to ESA therapy varies widely between different patient groups and individuals within those groups. In addition, an individual's response can vary greatly dependent on other clinical variables. During ESA initiation therapy, after drug dose adjustments or changes in an individual's clinical condition, more frequent monitoring is advised in order that under-treatment (ongoing anaemia) and overtreatment (rapidly rising Hb/hypertension or polycythaemia) may be avoided [1-3].

\section{Guideline 4.2 - Monitoring of treatment - Iron therapy}

We recommend regular monitoring of iron status (1-3 monthly) during treatment to avoid toxicity (1B): a serum ferritin consistently greater than $800 \mathrm{ng} / \mathrm{ml}$ is suggestive of iron overload. (1B)

\section{Rationale}

Intravenous iron therapy in particular has potential risks as well as benefits. Toxicity associated with high ferritin outcomes was originally reported in the context of multiple transfusions in the pre-ESA era. The risk persists that intravenous iron may reproduce similar toxicity and thus regular monitoring during therapy is required. Similarly with ongoing iron losses on HD regular monitoring to avoid worsening iron deficiency is required [1-3].

Clinical settings in which more frequent iron testing may be necessary include the following:

1. Initiation of ESA therapy

2. Achieving less-than-target $\mathrm{Hb}$ level during ongoing ESA therapy
3. Recent bleeding

4. After surgery

5. After hospitalisation

6. Monitoring response after a course of IV iron

7. Evaluation for ESA hypo-responsiveness

Guideline 4.3 - Monitoring during Intravenous Iron Administration

We recommend that resuscitative medication and personnel trained to evaluate and resuscitate anaphylaxis should be present at each administration of iron dextran. (1A)

\section{Rationale}

- All forms of IV iron may be associated with acute adverse events (AEs).

- Immune mechanisms (including mast cell mediated processes leading to a clinical syndrome resembling anaphylaxis) may have a role in some cases.

- Anaphylactoid reactions appear to occur more frequently with iron dextran [4].

- Labile or free iron reactions occur more frequently with nondextran forms of iron [5].

- The rate of life-threatening reactions to iron dextran administration is $0.6 \%$ to $0.7 \%[6,7]$.

- In patients receiving iron dextran, there remains a risk for significant $\mathrm{AE}$ in patients who had successfully received previous test or treatment doses suggesting that the risk for first-dose $\mathrm{AE}$ may recur in prevalent patients after an interval free from iron dextran exposure [8].

\section{Guideline 4.4 - Monitoring of treatment - Resistance to ESA therapy}

We recommend that inadequate response ('resistance') to ESA therapy is defined as failure to reach the target $\mathrm{Hb}$ level despite SC epoetin dose $>300 \mathrm{IU} / \mathrm{kg} /$ week (450 IU/ $\mathrm{kg} /$ week IV epoetin), or darbepoetin dose $>1.5 \mathrm{mcg} / \mathrm{kg} /$ week. Hyporesponsive patients who are iron replete should be screened clinically and by investigations for other common causes of anaemia. (1A)

\section{Audit measure}

Prevalence of resistance to ESA among renal replacement therapy patients

\section{Rationale}

Extensive publications are available on the topic of resistance to ESA therapy including the Revised European 
Best Practice Guidelines [9] which defines ESA resistance as above. Failure to respond at an earlier stage in therapy should however raise suspicion of ESA resistance. Comparison of the individual $\mathrm{Hb}$ outcome achieved and the dose of ESA used can provide a useful way of highlighting individuals that are ESA resistant during local unit audit $[10,11]$. ESA therapy is efficacious in most patients. However many conditions and treatment variables can cause or explain apparent resistance to ESA therapy. Adequate investigation and management of these underlying conditions is crucial in achieving satisfactory outcome haemoglobin values as well as requiring therapy in their own right.

Anti-erythropoietin antibody associated pure red cell aplasia (PRCA) is a very rare cause of resistance characterised by transfusion dependency, low reticulocyte count, lack of pro-erythroid progenitor cells in the bone marrow and neutralising anti-erythropoietin antibodies [12]. In 2005, a report concerning 170 CKD patients who developed epoetin-associated PRCA was made available by the Research on Adverse Drug Events and Reports (RADAR) Project [13]. Of the 34 patients who received epoetin after the onset of PRCA, $56 \%$ recovered epoetin responsiveness; the highest rate of epoetin responsiveness was observed among those who had no detectable anti-erythropoietin antibodies at the time of epoetin administration (89\%). Given these data, it is advisable that retreatment with ESA can be considered in patients with a history of PRCA if anti-EPO antibodies are no longer detectable.

\section{Guideline 4.5 - Monitoring of treatment - Hypertension during ESA therapy}

We recommend that blood pressure should be monitored in all patients receiving ESAs and, if present, hypertension be treated by volume removal and/or hypotensive drugs. (1A)

\section{Rationale}

Hypertension is the most common complication in CKD and can be aggravated by ESA treatment [9]. Early studies demonstrated higher incidence rates of hypertension though ESA doses used were higher and $\mathrm{Hb}$ responses faster in these trials. It is now more common to start at low doses and increase gradually according to response. The commonest cause of hypertension in CKD is not ESA therapy. Exacerbation of hypertension in ESA therapy patients may be associated with polycythaemia or rapidly rising haemoglobin levels. These complications should be looked for in hypertensive patients but in the absence of these complicating factors and in the absence of severe hypertension, ESA therapy can usually continue. Hypertension should be adequately controlled prior to initiating ESA therapy. ESA therapy should be discontinued in malignant hypertension.

\section{References}

1 National Collaborating Centre for Chronic Conditions, Royal College of Physicians. Guideline on Anaemia management in chronic kidney disease. 2006. National Institute for Clinical Excellence

-2 Locatelli F, Aljama P, Barany P et al. Revised European best practice Guidelines for the management of anaemia in patients with chronic renal failure. Nephrol Dial Transplant 2004;19(Suppl 2):ii1-47

- 3 NKF-K/DOQI Clinical Practice Guidelines for Anemia of Chronic Kidney Disease: update 2000. Am J Kidney Dis 2001;37:S182-S238

4 Novey HS, Pahl M, Haydik I, Vaziri ND. Immunologic studies of anaphylaxis to iron dextran in patients on renal dialysis. Ann Allergy 1994;72:224-228

5 Agarwal R, Vasavada N, Sachs NG, Chase S. Oxidative stress and renal injury with intravenous iron in patients with chronic kidney disease. Kidney Int 2004;65:2279-2289

6 Hamstra RD, Block MH, Schocket AL. Intravenous iron dextran in clinical medicine. JAMA 1980;243:1726-1731

7 Fishbane S, Ungureanu VD, Maesaka JK, Kaupke CJ, Lim V, Wish J. The safety of intravenous iron dextran in hemodialysis patients. Am J Kidney Dis 1996;28:529-534
8 Fletes R, Lazarus JM, Gage J, Chertow GM. Suspected iron dextranrelated adverse drug events in hemodialysis patients. Am J Kidney Dis 2001;37:743-749

$\checkmark 9$ Horl WH, Jacobs C, Macdougall IC et al. European Best Practice Guidelines 14-16: inadequate response to epoetin. Nephrol Dial Transplant 2000;15(Suppl 4):43-50

10 Winearls CG. Recombinant human erythropoietin: 10 years of clinical experience. Nephrol Dial Transplant 1998;13(Suppl 2):3-8

11 Jacobs C, Horl WH, Macdougall IC et al. European Best Practice Guidelines 5: target haemoglobin. Nephrol Dial Transplant 2000; 15(Suppl 4):15-19

12 Casadevall N, Nataf J, Viron B et al. Pure red-cell aplasia and antierythropoietin antibodies in patients treated with recombinant erythropoietin. N Engl J Med 2002;346:469-475

13 Bennett CL, Cournoyer D, Carson KR et al. Long-term outcome of individuals with pure red cell aplasia and anti-erythropoietin antibodies in patients treated with recombinant epoetin: a follow-up report from the Research on Adverse Drug Events and Reports (RADAR) Project. Blood 2005;106:3343-3347 


\section{Anaemia of CKD (Guidelines 5.1-5.2)}

\section{Guideline 5.1 - Blood Transfusion}

We recommend that in patients with anaemia of CKD, especially those in whom renal transplantation is an option, red blood cell transfusion should be avoided if possible. (1A)

\section{Guideline 5.2 - Blood Transfusion}

We recommend if red blood cell transfusion becomes essential (usually in the setting of acute blood loss, acute haemolysis or severe sepsis) transfusion should be based on policies set by local transfusion guidelines rather than $\mathrm{Hb}$ targets for ESA therapy in chronic anaemia of CKD. (1B)

\section{Audit measure}

Proportion of HD patients who received a blood transfusion within the past year

\section{Rationale for guidelines 5.1 and 5.2}

CKD results in chronic anaemia, the degree of which usually reflects the severity of CKD. As with any chronic anaemia, patients tend to deal with this by various compensatory mechanisms. Blood transfusion is rarely an acute requirement except in emergencies such as acute blood loss, acute haemolysis or severe sepsis/inflammation. Hence the risk benefit ratio of the intervention needs to be analysed before prescribing a red blood cell transfusion to treat anaemia in patients with chronic kidney disease.

The potential risks associated with blood transfusion include transfusion reactions, iron overload and transfusion acquired infections. In the presence of severe chronic anaemia, transfusion may lead to congestive cardiac failure, particularly in the elderly. A review of transfusion outcome in patients with acute coronary artery syndromes revealed a greater mortality rate in transfusion recipients [1]. Another review suggested that treatment of mild to moderate anaemia resulted in increased mortality [2]. Also transplant recipient sensitisation may occur following transfusion resulting in longer transplant register waiting times and difficulty in finding a cross match negative donor. A study from Ireland looking at causes of sensitisation of potential allograft recipients showed that the level of sensitisation increased with the number of units of blood transfused and also demonstrated a direct relationship between degree of sensitisation and waiting time for transplantation [3]. Blood transfusions can induce antibodies to histocompatibility leukocyte antigens that can reduce the success of kidney transplantation; thus transfusions generally should be avoided in patients awaiting a renal transplant [4].

The use of ESAs can greatly reduce the need for red blood cell transfusions in patients with anaemia of $\mathrm{CKD}$ when target $\mathrm{Hb}$ concentrations are achieved and maintained [5-6]. Since the introduction of ESAs and reduction in routine blood transfusion in anaemic patients with CKD sensitisation has markedly reduced [7]. With the advent of new immunosuppressant regimens after 1995, the use of pretransplantation transfusion have been rendered largely obsolete [8]. The KDOQI anaemia guideline recommends that no single $\mathrm{Hb}$ concentration justifies or requires transfusion and the target $\mathrm{Hb}$ recommended for chronic anaemia management should not serve as a transfusion trigger [8]. NICE agrees that there are clinical reasons to minimise blood transfusion in anaemia of CKD and if blood transfusion is essential the relevant haematology guidelines should be followed (e.g. the British Committee for Standards in Haematology (BCSH) guidelines www.bcshguidelines.com) [9].

\section{References}

1 Rao SV, Jollis JG, Harrington RA et al. Relationship of blood transfusion and clinical outcomes in patients with acute coronary syndromes. JAMA 2004;292(13):1555-1562

-2 Zarychanski R, Houston DS. Anemia of chronic disease: a harmful disorder or an adaptive, beneficial response? CMAJ 2008;179(4):333-337

-3 Soosay A, O’Neill D, Counihan A, Hickey D, Keogan M. Causes of sensitisation in patients awaiting renal transplantation in Ireland. Ir Med J 2003;96(4):109-112

4 Eschbach JW. The anemia of chronic renal failure: Pathophysiology and the effects of recombinant erythropoietin. Kidney Int 1989;35(1):134148.
5 House AA, Pham B, Pagé DE. Transfusion and recombinant human erythropoietin requirements differ between dialysis modalities. Nephrol Dial Transplant 1998;13(7):1763-1769

6 Popovsky MA, Ransil BJ. Long-term impact of recombinant human erythropoietin on transfusion support in patients with chronic renal failure. Immunohematology 1996;12(1):1-3

7 Manchester Kidney Transplant, NWKTA Audit Project, Jan 2003

8 NKF-K/DOQI Clinical Practice Guidelines for Anemia of Chronic Kidney Disease: 2006

9 Guideline on anaemia management in chronic kidney disease. 2006. National Institute for Health and Clinical Excellence 


\section{Anaemia of CKD (Guideline 6.1)}

\section{Guideline 6.1 - Post-transplantation Anaemia}

We recommend that the treatment guidelines for anaemia in renal transplant patients should be similar to those for CKD patients not on dialysis. (1B)

\section{Rationale}

Post transplantation Anaemia (PTA) is common [13]. Apart from the usual causes of anaemia due to $\mathrm{CKD}$, renal transplant recipients have various unique factors predisposing to anaemia.

Factors causing PTA:

1. GFR: anaemia in transplant patients reflects the degree of GFR similar to other patients with CKD [3].

2. Immunosuppressive medications: Mycophenolate and azathioprine are myelosuppressive agents. Calcineurin inhibitors may cause anaemia by microangiopathic haemolysis [4-8]. OKT3 may also cause haemolytic uraemic syndrome (HUS) $[9,10]$. Sirolimus has also been associated with anaemia [11-13]. It may interfere with post erythropoietin receptor binding intracellular signalling and may occasionally cause HUS $[13,14]$.

3. Angiotensin converting enzyme (ACE) inhibitor and angiotensin receptor blocker (ARB) use: ACE inhibition has been linked with anaemia $[3,15]$. Its pathogenesis is multifactorial and may include inhibition of endogenous EPO production, production of an erythropoiesis-inhibiting protein [16] and inhibition of angiotensin II mediated stimulation of erythrocyte precursors [17].

4. Antibiotic use: various common antibiotics may cause anaemia including trimethoprim-sulfamethoxazole.

5. Infections: viral infections such as cytomegalovirus and parvovirus B19 and antiviral agents such as ganciclovir may cause anaemia in transplant patients $[18,19]$.

6. Malignancy: malignancies including post transplant lymphoproliferative disorder may result in anaemia.

7. Haemolytic anaemia: haemolytic anaemia may result from HUS or minor blood group incompatibility in transplant patients [20-22].

8. Rejection episodes: Acute rejection may cause reduced endogenous EPO production [23]. Severe vascular rejection may cause microangiopathy.

9. Chronic inflammation: Failing renal transplant causes a chronic inflammatory state resulting in EPO hyporesponsiveness.

Safety of ESA in transplant patients:

A few early retrospective studies suggested increased incidence of delayed graft function in patients on ESA prior to transplantation [24, 25]. However Registry data has since shown reduced incidence of delayed graft function despite increasing use of ESA. It has also been shown that ESA use prior to renal transplantation does not reduce production of or response to endogenous EPO [26, 27]. Studies in the early post transplant period did not show significant adverse events including delayed graft function or hypertension $[28,29]$. Studies in the late transplant period have shown increased incidence of hypertension [30, 31]. ESAs, most probably, do not accelerate rate of graft function decline and one study suggested that correction of anaemia slowed the decline in allograft function [32].

Efficacy of ESA in transplant patients:

Studies in the early post transplant period have shown that ESA is effective in these patients, although the dose required may be higher than in pretransplant period [28, 29]. Similarly studies in late post transplant period have shown efficacy of ESA in these patients [30-31, 33-34]. 


\section{References}

1 Yorgin PD, Scandling JD, Belson A, Sanchez J, Alexander SR, Andreoni KA. Late post-transplant anemia in adult renal transplant recipients. An under-recognised problem? Am J Transplant 2002;2(5):429-435

2 Yorgin PD, Belson A, Sanchez J, Al Uzri AY, Sarwal M, Bloch DA, Oehlert J, Salvatierra O, Alexander SR. Unexpectedly high prevalence of posttransplant anemia in pediatric and young adult renal transplant recipients. Am J Kidney Dis 2002;40(6):1306-1318

- 3 Vanrenterghem Y, Ponticelli C, Morales JM, Abramowicz D, Baboolal K, Eklund B, Kliem V, Legendre C, Morais Sarmento AL, Vincenti F. Prevalence and management of anemia in renal transplant recipients: A European survey. Am J Transplant 2003;3(7):835-845

4 Abraham KA, Little MA, Dorman AM, Walshe JJ. Hemolytic-uremic syndrome in association with both cyclosporine and tacrolimus. Transpl Int 2000;13(6):443-437

- 5 Epstein M, Landsberg D. Cyclosporine-induced thrombotic microangiopathy resulting in renal allograft loss and its successful reuse: A report of two cases. Am J Kidney Dis 1991;17(3):346-348

6 Pham PT, Peng A, Wilkinson AH, Gritsch HA, Lassman C, Pham PC, Danovitch GM. Cyclosporine and tacrolimus-associated thrombotic microangiopathy. Am J Kidney Dis 2000;36(4):844-850

7 Trimarchi HM, Truong LD, Brennan S, Gonzalez JM, Suki WN. Report of two cases and review of the literature. Transplantation 1999;67(4): 539-544

$\checkmark 8$ Zarifian A, Meleg-Smith S, O’Donovan R, Tesi RJ, Batuman V. Cyclosporine-associated thrombotic microangiopathy in renal allografts. Kidney Int 1999;55(6):2457-2466

-9 Dussol B, Brunet P, Vacher-Coponat H, Saingra Y, Casanova P, Berland Y. Haemolytic uraemic syndrome in a renal transplant recipient during OKT3 therapy. Nephrol Dial Transplant 1994;9(8):1191-1193

10 Morris-Stiff G, Evans M, Baboolal K, Balaji V, Moore R, Jurewicz A, Lord R. Haemolytic uraemic syndrome associated with OKT3. Transpl Int 1996;9(5):522-523

11 MacDonald AS, RAPAMUNE Global Study Group. A worldwide, phase III, randomized, controlled, safety and efficacy study of a sirolimus/ cyclosporine regimen for prevention of acute rejection in recipients of primary mismatched renal allografts. Transplantation 2001;71(2):271280

12 Kahan BD, Knight R, Schoenberg L, Pobielski J, Kerman RH, Mahalati K, Yakupoglu Y, Aki FT, Katz S, Van Buren CT. Ten years of sirolimus therapy for human renal transplantation: The University of Texas at Houston experience. Transplant Proc 2003;35(3 Suppl):25S-34S

13 Augustine JJ, Knauss TC, Schulak JA, Bodziak KA, Siegel C, Hricik DE. Comparative effects of sirolimus and mycophenolate mofetil on erythropoiesis in kidney transplant patients. Am J Transplant 2004; 4(12):2001-2006

14 Crew RJ, Radhakrishnan J, Cohen DJ, Stern L, Goldstein M, Hardy M, D'Agati VD, Markowitz GS. De novo thrombotic microangiopathy following treatment with sirolimus: Report of two cases. Nephrol Dial Transplant. 2005;20(1):203-209

15 Winkelmayer WC, Kewalramani R, Rutstein M, Gabardi S, Vonvisger T, Chandraker A. Pharmacoepidemiology of anemia in kidney transplant recipients. J Am Soc Nephrol. 2004;15(5):1347-1352

16 Le Meur Y, Lorgeot V, Comte L, Szelag JC, Aldigier JC, Leroux-Robert C, Praloran V. Plasma levels and metabolism of AcSDKP in patients with chronic renal failure: Relationship with erythropoietin requirements. Am J Kidney Dis. 2001;38(3):510-517

17 Naito M, Kawashima A, Akiba T, Takanashi M, Nihei H. Effects of an angiotensin II receptor antagonist and angiotensin-converting enzyme inhibitors on burst forming units-erythroid in chronic hemodialysis patients. Am J Nephrol. 2003;23(5):287-293. Epub 2003 Jul 31

18 So BJ, Chae KM, Lee KK, Lee YJ, Jeong BH. Pure red cell aplasia due to parvovirus B19 infection in a renal transplant patient: A case report. Transplant Proc. 2000;32(7):1954-1956

19 Vales-Albertos LJ, García-Cárdenas M, Chávez-Becerra S, GómezNavarro B, Monteón-Ramos F, Cueto-Manzano AM. Pure red cell aplasia associated with parvovirus B19 infection in renal transplantation: The first case report in Mexico. Transplantation. 2005; 79(6):739

20 Debska-Slizień A, Chamienia A, Król E, Zdrojewski Z, Pirski I, Zadrozny D, Sledziński Z, Rutkowski B. Hemolytic anemia after renal transplantation: Analysis of case reports. Transplant Proc. 2003;35(6): 2233-2237

21 Peces R, Díaz Corte C, Navascués RA. [Hemolytic anemia caused by graft-versus-host reaction in $\mathrm{ABO}$-nonidentical renal transplants from blood group O donors.] Nefrologia. 2001;21(4):395-401

22 Li FK, Chan TM, Lai KN: Alloimmune hemolysis after renal transplantation. Am J Nephrol. 2000;20(6):473-475

23 Moulin B, Ollier J, George F, Purgus R, Roux F, Sampol J, Olmer M. Serum erythropoietin and reticulocyte maturity index after renal transplantation: A prospective longitudinal study. Nephron. 1995; 69(3):259-266

24 Schmidt R, Kupin W, Dumler F, Venkat KK, Mozes M. Influence of the pretransplant hematocrit level on early graft function in primary cadaveric renal transplantation. Transplantation 1993;55(5):1034-1040

25 Vasquez EM, Pollak R. Effect of pretransplant erythropoietin therapy on renal allograft outcome. Transplantation. 1996;62(7):1026-1028

26 Paganini EP, Braun WE, Latham D, Abdulhadi MH. Renal transplantation: results in hemodialysis patients previously treated with recombinant human erythropoietin. ASAIO Trans. 1989;35(3):535-538

27 Lee DB: Interrelationship between erythropoietin and erythropoiesis: Insights from renal transplantation. Am J Kidney Dis. 1991;18(4 Suppl 1):54-56

28 Van Loo A, Vanholder R, Bernaert P, De Roose J, Lameire N. Recombinant human erythropoietin corrects anaemia during the first weeks after renal transplantation: A randomized prospective study. Nephrol Dial Transplant. 1996;11(9):1815-1821

29 Van Biesen W, Vanholder R, Veys N, Verbeke F, Lameire N. Efficacy of erythropoietin administration in the treatment of anemia immediately after renal transplantation. Transplantation. 2005;79(3):367-368

30 Jindal KK, Hirsch DJ, Belitsky P, Whalen MA. Low-dose subcutaneous erythropoietin corrects the anaemia of renal transplant failure. Nephrol Dial Transplant. 1992;7(2):143-146

- 31 Muirhead N, Cattran DC, Zaltzman J, Jindal K, First MR, Boucher A, Keown PA, Munch LC, Wong C. Safety and efficacy of recombinant human erythropoietin in correcting the anemia of patients with chronic renal allograft dysfunction. J Am Soc Nephrol. 1994;5(5):1216-1222

- 32 Becker BN, Becker YT, Leverson GE, Heisey DM. Erythropoietin therapy may retard progression in chronic renal transplant dysfunction. Nephrol Dial Transplant. 2002;17(9):1667-1673

- 33 Traindl O, Barnas U, Franz M, Falger S, Klauser R, Kovarik J, Graf H. Recombinant human erythropoietin in renal transplant recipients with renal anemia. Clin Transplant. 1994;8(1):45-48

34 Yoshimura N, Oka T, Ohmori Y, Aikawa I. Effects of recombinant human erythropoietin on the anemia of renal transplant recipients with chronic rejection. Transplantation. 1989;48(3):527-529. 


\section{Acknowledgements}

Dr Ashraf Mikhail wishes to declare the following conflicts of interest: Study investigator for research studies sponsored by Amgen, Roche, Affymax \& Takeda, receipt of sponsorship to attend scientific meetings from Amgen, Roche and Johnson \& Johnson, and receipt of consultancy fees from Amgen, Roche, Astellas, Takeda and Lipoxen.

Dr Donald Richardson wishes to declare the following conflicts of interest: Study investigator for research studies sponsored by Amgen, receipt of sponsorship to attend scientific meetings from Roche and Baxter, and received payment for lectures on renal anaemia and use of computerised decision support from Amgen, Roche, Vifor and Johnson \& Johnson.

Dr Rajesh Shrivastava wishes to declare the following conflicts of interest: Receipt of sponsorship to attend scientific meetings from Roche.

We are grateful for comments received from:

Dr David Goldsmith, Renal Unit, Guy's and St Thomas' NHS Foundation Hospital, London
Dr Philip Kalra, Renal Unit, Salford Royal Hospital Trust

Dr Elizabeth Lindley, Department of Renal Medicine, St James's University Hospital, Leeds

Dr Peter Andrews, Renal Unit, Epsom and St Helier University Hospital

Dr Colin Jones, Renal unit, York Hospital

Dr Mahzuz Karim, Renal Unit, Norfolk and Norwich University Hospital

Christopher Brown, Renal Pharmacist, Morriston Hospital, Swansea

George Peebles, Renal Anaemia Specialist Nurse, Department of Renal Medicine, Sunderland Royal Hospital Gill Donaldson, Business Manager, Ortho Biotech Dr Wendy Mills, Medical Director, Vitaline Pharmaceuticals

Svend Lorentz Jorgensen, Vice President, Medical Affairs, Pharmacosmos 